\title{
Ice cloud processing of ultra-viscous/glassy aerosol particles leads to enhanced ice nucleation ability
}

\author{
R. Wagner ${ }^{1}$, O. Möhler ${ }^{1}$, H. Saathoff ${ }^{1}$, M. Schnaiter ${ }^{1}$, J. Skrotzki ${ }^{1}$, T. Leisner ${ }^{1}$, T. W. Wilson ${ }^{2}$, T. L. Malkin ${ }^{2}$, and \\ B. J. Murray ${ }^{2}$ \\ ${ }^{1}$ Karlsruhe Institute of Technology, Institute for Meteorology and Climate Research, Karlsruhe, Germany \\ ${ }^{2}$ School of Earth and Environment, Woodhouse Lane, University of Leeds, Leeds LS2 9JT, UK
}

Correspondence to: R. Wagner (robert.wagner2@kit.edu)

Received: 7 March 2012 - Published in Atmos. Chem. Phys. Discuss.: 10 April 2012

Revised: 17 July 2012 - Accepted: 25 July 2012 - Published: 25 September 2012

\begin{abstract}
The ice nucleation potential of airborne glassy aqueous aerosol particles has been investigated by controlled expansion cooling cycles in the AIDA aerosol and cloud chamber of the Karlsruhe Institute of Technology at temperatures between 247 and $216 \mathrm{~K}$. Four different solutes were used as proxies for oxygenated organic matter found in the atmosphere: raffinose, 4-hydroxy-3-methoxy-DL-mandelic acid (HMMA), levoglucosan, and a multi-component mixture of raffinose with five dicarboxylic acids and ammonium sulphate. Similar to previous experiments with citric acid aerosols, all particles were found to nucleate ice heterogeneously before reaching the homogeneous freezing threshold provided that the freezing cycles were started well below the respective glass transition temperatures of the compounds; this is discussed in detail in a separate article. In this contribution, we identify a further mechanism by which glassy aerosols can promote ice nucleation below the homogeneous freezing limit. If the glassy aerosol particles are probed in freezing cycles started only a few degrees below their respective glass transition temperatures, they enter the liquid regime of the state diagram upon increasing relative humidity (moisture-induced glass-to-liquid transition) before being able to act as heterogeneous ice nuclei. Ice formation then only occurs by homogeneous freezing at elevated supersaturation levels. When ice forms the remaining solution freeze concentrates and re-vitrifies. If these ice cloud processed glassy aerosol particles are then probed in a second freezing cycle at the same temperature, they catalyse ice formation at a supersaturation threshold between 5 and $30 \%$ with respect to ice. By analogy with the enhanced ice nucleation ability of insoluble ice nuclei like mineral dusts af-
\end{abstract}

ter they nucleate ice once, we refer to this phenomenon as pre-activation. We propose a number of possible explanations for why glassy aerosol particles that have re-vitrified in contact with the ice crystals during the preceding homogeneous freezing cycle exhibit pre-activation: they may retain small ice embryos in pores, have footprints on their surface which match the ice lattice, or simply have a much greater surface area or different surface microstructure compared to the unprocessed glassy aerosol particles. Pre-activation must be considered for the correct interpretation of experimental results on the heterogeneous ice nucleation ability of glassy aerosol particles and may provide a mechanism of producing a population of extremely efficient ice nuclei in the upper troposphere.

\section{Introduction}

Several recent studies have addressed the hygroscopic behaviour, reactivity, and ice nucleation ability of glassy aerosol particles (Bodsworth et al., 2010; Koop et al., 2011; Li et al., 2011; Mikhailov et al., 2009; Murray, 2008b; Murray et al., 2010, 2012; Shiraiwa et al., 2011; Tong et al., 2011; Zobrist et al., 2008, 2011). In the atmosphere, glassy particles can be formed when the viscosity of liquid aerosol particles containing oxygenated organic compounds attains values larger than $10^{12} \mathrm{~Pa}$ s upon cooling, transforming the liquid into an amorphous, non-crystalline solid (Debenedetti and Stillinger, 2001; Murray, 2008b). In the amorphous state, the reversible hygroscopic growth that is characteristic for liquid aqueous solution droplets is kinetically limited due 
to the extremely small diffusion coefficients, $D_{\mathrm{H}_{2} \mathrm{O}}$, of water molecules (Li et al., 2011; Mikhailov et al., 2009). For example, $D_{\mathrm{H}_{2} \mathrm{O}}$ values as low as $10^{-24} \mathrm{~m}^{2} \mathrm{~s}^{-1}$ were found for aqueous sucrose glasses at temperatures down to $203 \mathrm{~K}$ (Zobrist et al., 2011). The retarded water uptake and water release in humidifying and drying cycles leads to negative and positive deviations of the particle radius compared to the value computed for equilibrium conditions. By adopting a spherical shell diffusion model to replicate the measured water uptake and release of single levitated sucrose particles, Zobrist et al. (2011) have shown that strong concentration gradients within a single particle can form, e.g., a glassy skin that separates the still liquid centre of a particle from the surrounding gas phase. Tong et al. (2011) have shown that there is a time delay of several 10 to 100 seconds before an initially glassy particle of $1-8 \mu \mathrm{m}$ in radius returns to equilibrium conditions when the relative humidity is increased from below $\mathrm{RH}_{\mathrm{g}}$ to above $\mathrm{RH}_{\mathrm{g}}$, with $\mathrm{RH}_{\mathrm{g}}$ denoting the glass transition relative humidity. Such gradual deliquescence transition when going from amorphous to liquid particles has also been observed by Mikhailov et al. (2009) for levoglucosan aerosol particles. Murray et al. (2012) show how the shards of shattered glassy droplets gradually merge to form a single droplet on increasing RH using optical and Raman microscopy.

Concerning their ice nucleation ability, Murray et al. (2010) have detected that glassy aerosol particles are able to act as heterogeneous ice nuclei. In their study, citric acid aerosol particles were used as a proxy for atmospheric oxygenated organic compounds and were probed in expansion experiments that were conducted at the Aerosol Interactions and Dynamics in the Atmosphere (AIDA) cloud simulation chamber of the Karlsruhe Institute of Technology. A useful quantity for the interpretation of the temperature-dependent ice nucleation behaviour observed in AIDA is the temperature $T_{\mathrm{g}}^{\prime}$ that is defined as the intersection between the curves of the glass transition temperatures, $T_{\mathrm{g}}$, and the ice melting temperatures, $T_{\mathrm{m}}$, in the state diagram (Zobrist et al., 2008). This is because the AIDA expansion runs are started at almost ice-saturated conditions in the chamber volume (see Sect. 3), so that the composition of liquid citric acid aerosol particles prior to the expansion runs adjusts approximately to that defined by the $T_{\mathrm{m}}$ curve. For citric acid, $T_{\mathrm{g}}^{\prime}$ is at about $212 \mathrm{~K}$. For a chamber temperature above $212 \mathrm{~K}$, the aerosol particles were therefore initially in a liquid state, resulting in homogeneous freezing of the citric acid aerosol particles in the corresponding expansion run at a relative humidity similar to liquid sulphuric acid droplets. Below $212 \mathrm{~K}$, a much smaller number fraction of the now glassy citric acid particles heterogeneously nucleated ice over a range of relative humidities below the homogeneous freezing threshold. It was shown by a one-dimensional cirrus model that this nucleation pathway might explain low ice particle number concentrations and high in-cloud relative humidities observed at low temperatures for tropical tropopause layer cirrus clouds (Murray et al., 2010).

In a series of new AIDA cloud chamber experiments, we have probed four different glassy aqueous organic compounds for their ice nucleation ability. We have chosen solutions whose state diagrams in the water activity scale have been characterised in the study by Zobrist et al. (2008). The compounds feature a diverse chemical functionality and, as addressed below, can be considered as representative of organic atmospheric aerosol. Two of these solutes, levoglucosan and the multi-component mixture raffinose/M5AS (M5: mixture of five dicarboxylic acids, AS: ammonium sulphate), have similar $T_{\mathrm{g}}^{\prime}$ temperatures to citric acid. The two other solutes, pure raffinose and 4-hydroxy-3-methoxy-DLmandelic acid (HMMA), have much higher $T_{\mathrm{g}}^{\prime}$ temperatures of 240 and $236 \mathrm{~K}$, respectively. These solutions allow us to investigate the heterogeneous ice nucleation ability of glassy aerosol particles over an extended temperature range. In a companion paper, we show that heterogeneous ice nucleation is a common property of all investigated species if the aerosol particles are initially deep in the glassy state, i.e., if the starting temperature of the expansion runs was well below $T_{\mathrm{g}}^{\prime}$ (Wilson et al., 2012). As already observed in the citric acid experiments, heterogeneous ice nucleation became much less efficient when the initial chamber temperature approached $T_{\mathrm{g}}^{\prime}$. The glassy aqueous raffinose particles, for example, acted as heterogeneous ice nuclei only at temperatures below about $215 \mathrm{~K}$. Between 215 and $240 \mathrm{~K}\left(T_{\mathrm{g}}^{\prime}\right)$, although initially still being in the glassy regime, homogeneous freezing was observed in the first expansion run conducted with the injected aerosol load. After the ice cloud from this first expansion run had sublimed, we started a second expansion run at the same temperature and with these cloud processed aerosol particles. In this second run, ice nucleation was detected at very low supersaturation levels well below that required for homogeneous freezing.

In the following, we term this enhanced ice nucleation ability of ice cloud processed glassy particles as preactivation behaviour to distinguish it from heterogeneous ice nucleation in the deposition mode which always occurs at temperatures well below $T_{\mathrm{g}}^{\prime}$. The second expansion cycle after the preceding homogeneous freezing run where the preactivation behaviour becomes evident will be called the preactivation run. The term "pre-activation" is a well-known phenomenon in heterogeneous ice nucleation, representing a "memory" effect where insoluble ice nuclei show an enhanced ice nucleation ability after they have already been involved in ice crystal formation (Pruppacher and Klett, 1997). As discussed later in this article, a similar mechanism is the most likely explanation for our observations and we therefore chose to use the term pre-activation throughout the manuscript text.

The pre-activation behaviour of ice cloud processed glassy aerosol particles at temperatures slightly below $T_{\mathrm{g}}^{\prime}$ will be the topic of the present manuscript, whereas, as indicated above, 


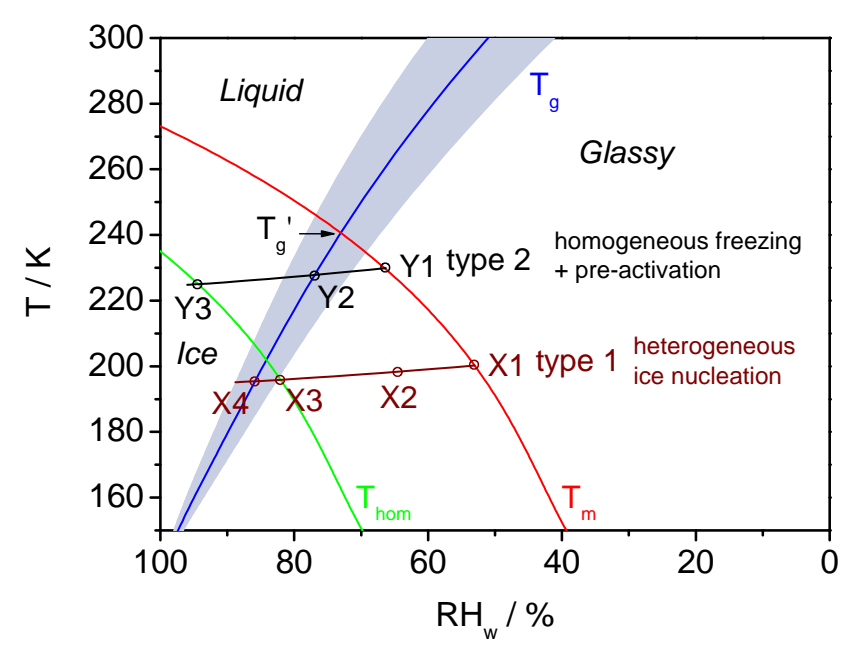

Fig. 1. Experimental trajectories (black and brown lines) of two types of AIDA expansion runs with aqueous raffinose aerosol particles as a function of the relative humidity with respect to liquid water, $\mathrm{RH}_{\mathrm{W}} . T_{\mathrm{g}}$ denotes the glass transition temperature, $T_{\mathrm{m}}$ the ice melting temperature, and $T_{\text {hom }}$ the homogeneous freezing temperature. The computations of these curves as well as the details of the labelled points along the trajectories are discussed in the text.

the results for heterogeneous ice nucleation on the glassy aerosol particles at temperatures clearly below $T_{\mathrm{g}}^{\prime}$ are described by Wilson et al. (2012). As a supplementary information for the reader, we summarise in Table A1 of Appendix A the upper threshold temperatures and associated supersaturation levels where heterogeneous ice nucleation in the deposition mode on the various glassy aerosol particles has been observed. Our manuscript explicitly addresses the ice nucleation behaviour of the various compounds in the glassy regime above these threshold temperatures for heterogeneous ice nucleation. Table A1 additionally includes the $T_{\mathrm{g}}^{\prime}$ values as well as brief description of the chemical functionality and atmospheric significance of the investigated compounds, as discussed in detail in the introduction of our companion paper (Wilson et al. (2012) and references therein).

In the next section, we further introduce the subject of our present experiments and the methodology of the AIDA cloud expansion runs on the basis of the raffinose/water state diagram. The technical operation of the AIDA chamber will be described in Sect. 3. In Sect. 4, we present and discuss our new findings and then conclude our manuscript with a summary in Sect. 5.

\section{Methodology of the AIDA cloud expansion experiments}

Figure 1 shows the experimental trajectories of two types of AIDA expansion cooling experiments with aqueous raffinose aerosol particles as a function of the relative humidity, $\mathrm{RH}_{\mathrm{w}}$, of the air (black and brown lines). Type 1, started at $200 \mathrm{~K}$, addresses heterogeneous ice nucleation deeply in the glassy regime whereas type 2 , started at $230 \mathrm{~K}$, represents the homogeneous freezing - pre-activation behaviour. The homogeneous ice freezing and ice melting point curves according to Koop et al. (2000) as well as the glass temperature curve for raffinose according to Zobrist et al. (2008) are shown as green, red, and blue lines, respectively. The shaded blue area represents the uncertainty regime of the glass curve, as calculated from the uncertainties given in Table A3 of Zobrist et al. (2008). Note that these uncertainties only address the parameterisation of $T_{\mathrm{g}}$ as a function of the raffinose weight fraction. A further uncertainty might arise from the conversion of the weight fraction to the RH scale. For this conversion, another parameterisation provided by Zobrist et. al (2008) was employed, extrapolating water activity measurements for raffinose solutions of different concentrations in the temperature range from 289 to $313 \mathrm{~K}$ to lower temperatures.

As described in Sect. 3, the inner walls of the AIDA chamber are coated by a thin ice layer in preparation for the expansion runs. Prior to an expansion, $\mathrm{RH}_{\mathrm{w}}$ is thus controlled by the ice coating on the chamber walls and the starting points of the two trajectories are given approximately by the points $\mathrm{X} 1$ and $\mathrm{Y} 1$ on the ice melting point curve. Usually, the chamber was kept at a temperature above $T_{\mathrm{g}}^{\prime}$ for aerosol injection and was then cooled to the starting temperature of the expansion runs. Upon cooling, the injected aqueous solution droplets will only equilibrate to the ambient relative humidity which is given by the ice-melting point curve as long as the temperature is above $T_{\mathrm{g}}^{\prime}$. Further cooling below $T_{\mathrm{g}}^{\prime}$ causes the aerosol particles to vitrify, thereby greatly increasing the equilibration times (Tong et al., 2011; Zobrist et al., 2011). Hence the ambient RH no longer equals the water activity of the aerosol particles.

To mimic the expansion cooling of rising air parcels in the atmosphere, the AIDA pressure is reduced by controlled pumping. This leads to a decrease in the gas temperature and an increase in the relative humidity. Along the course of trajectory type 1 , the glass transition relative humidity (point $\mathrm{X} 4$ ) is above the relative humidity for homogeneous freezing (X3). If heterogeneous ice nucleation by deposition mode nucleation were inefficient as previously assumed by Zobrist et al. (2008), one would expect a gradual glass-to-liquid transition upon surpassing point $\mathrm{X} 4$ along the trajectory, followed by the nucleation of ice when the now liquid raffinose solution droplets have taken up enough water to become sufficiently dilute for homogeneous freezing to occur. Actually, we have observed heterogeneous ice nucleation on a subset of the aerosol particles starting at only $\sim 65 \% \mathrm{RH}_{\mathrm{w}}$ (point $\mathrm{X} 2$ ) along the trajectory (Wilson et al., 2012). It then depends on the cooling rate of the experiment and the number concentration of the nucleated ice crystals whether the supersaturation is sufficiently quenched or whether the RH would further increase beyond point X4 during continued pumping 


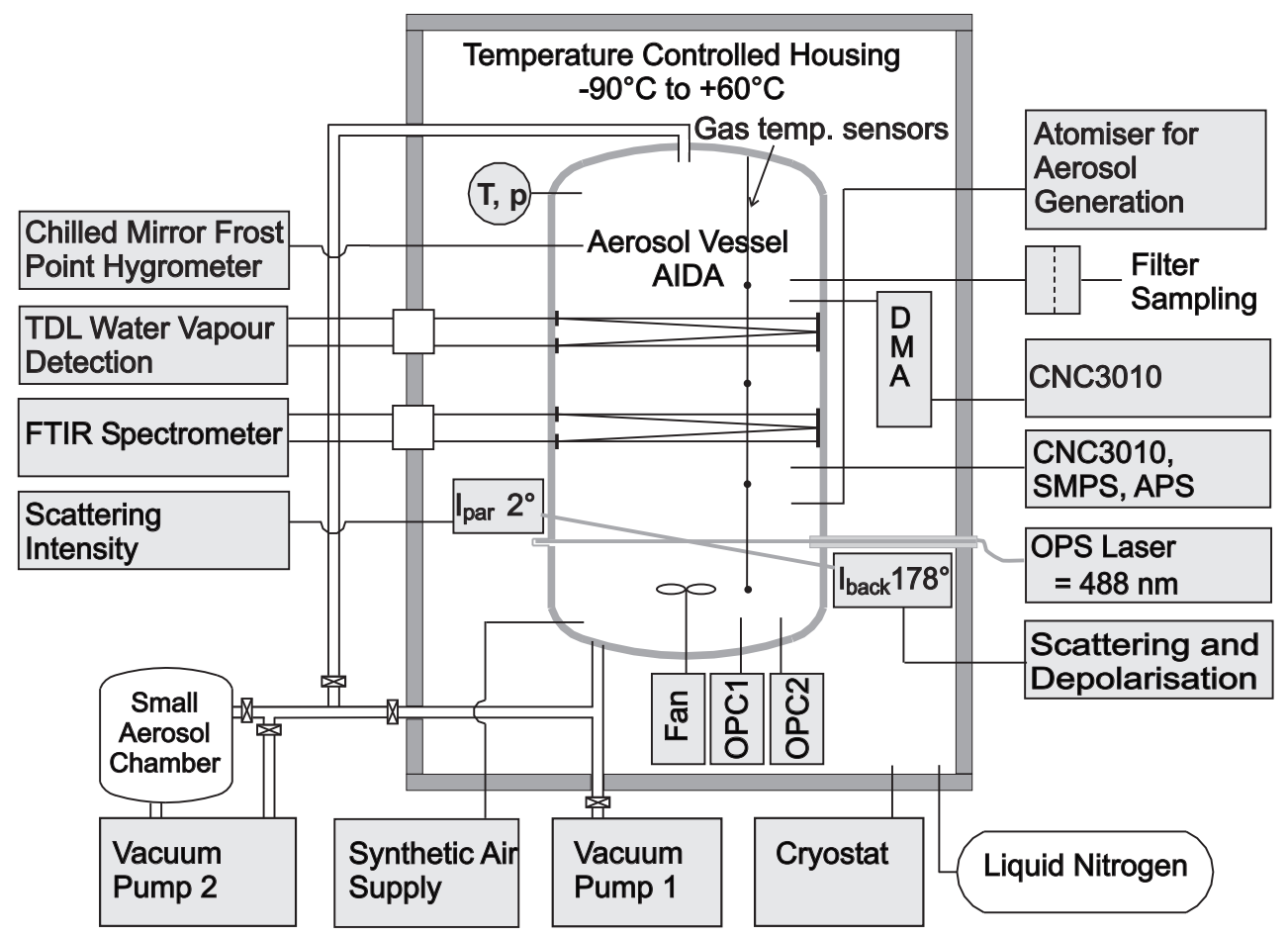

Fig. 2. Scheme of the AIDA aerosol and cloud chamber facility, showing the standard instrumentation for the ice nucleation experiments.

to lead to an additional nucleation mode by homogeneous freezing.

Trajectory type 2 represents a typical scenario for the experiments described in this manuscript. The starting temperature of the expansion run is slightly below $T_{\mathrm{g}}^{\prime}$ and along the course of the trajectory first $\mathrm{RH}_{\mathrm{g}}$ (Y2) and then the relative humidity for homogeneous freezing (Y3) are surpassed. For trajectories just below the $T_{\mathrm{g}}^{\prime}$ we did not typically observe heterogeneous ice formation in the first expansion run. Instead, ice nucleated at the homogeneous freezing limit at exactly the same relative humidity as previously detected for the homogeneous freezing of supercooled sulphuric acid solution droplets (Möhler et al., 2003). This indicates that the gradual glass-to-liquid transition at point Y2 did not retard homogeneous ice nucleation under our experimental conditions. The homogeneously nucleated ice crystals then rapidly depleted the excess of water vapour in the gas phase on a typical time scale of about one minute. The freeze concentrated raffinose solution that was rejected from the ice phase re-entered the glassy regime and again vitrified (Zobrist et al., 2008). After the sublimation of the ice cloud that was formed in this first expansion cycle, the ice cloud processed glassy aqueous raffinose particles were probed for their ice nucleation ability in a second expansion run at the same temperature. In the second run, we observed a distinct early ice crystal mode well before reaching the homogeneous freezing limit which was absent in the first run. We further dis- cuss and provide the most reasonable explanation for this pre-activation behaviour in Sect. 4 .

\section{Methods}

\subsection{Ice nucleation studies in the AIDA expansion cloud chamber}

The AIDA chamber is a cylindrical aluminium vessel of $4 \mathrm{~m}$ diameter and $84.3 \mathrm{~m}^{3}$ volume which is located inside an isolating container whose interior can be cooled to $183 \mathrm{~K}$ by evaporating liquid nitrogen inside two heat exchangers (Fig. 2) (Wagner et al., 2006b). The temperature is controlled by ventilating air around the aerosol vessel and a mixing fan is continuously operating inside the vessel to ensure for homogeneous conditions in terms of temperature, relative humidity, as well as aerosol and ice particle number concentration throughout the chamber volume. The aerosol vessel is cleaned by pumping to a pressure below $1 \mathrm{hPa}$ and performing a series of flushing cycles with particle-free synthetic air. Then, a specific amount of purified water from a heated reservoir is evaporated into the evacuated chamber. Water is added in excess to induce ice coverage of the inner chamber walls. After humidification, the chamber is refilled to ambient pressure with particle-free synthetic air. The particle background prior to aerosol injection is typically well below $1 \mathrm{~cm}^{-3}$. Due to the ice covered chamber walls, the relative humidity of the air is close to an ice saturation ratio, $S_{\text {ice }}$, of unity, with 
$S_{\text {ice }}$ denoting the ratio of the prevailing water vapour pressure, $p_{\mathrm{w}}(T)$, to the saturation water vapour pressure over ice, $p_{\mathrm{w}, \text { ice }}(T)$ (Murphy and Koop, 2005), at the same temperature. The water vapour pressure, both under cloud-free and in-cloud conditions, is measured in situ with high-resolution tuneable diode laser (TDL) absorption spectroscopy at nearinfrared wavelengths between 1368 and $1372 \mathrm{~nm}$ with an uncertainty of $\pm 5 \%$. The absolute accuracy of $p_{\mathrm{w}}(T)$ is mainly determined by the uncertainty of the line strength of the rovibrational water vapour transition that is scanned during the measurements (Wagner et al., 2008).

After the preparation of the chamber, dilute aqueous solutions of the investigated organic compounds were injected into the chamber as described in the Sect. 3.2. To investigate the ice nucleation ability of the generated organic aerosol particles, supersaturations with respect to the ice phase have to be established. This is achieved by expansion cooling, i.e., the AIDA pressure is reduced by controlled pumping, typically from ambient pressure to about $800 \mathrm{hPa}$. Depending on the pumping speed, humidification rates, $d S_{\text {ice }} / d t$, between about 0.02 and $0.3 \mathrm{~min}^{-1}$ can be controlled. The potential formation of ice clouds is detected by a comprehensive set of instruments whose details are described in a recent review and will therefore only briefly be summarised here (Wagner et al., 2009).

The number concentration of nucleated ice crystals is measured by two optical particle counters (OPC1 and OPC2, type WELAS2000, Palas GmbH Karlsruhe) that are located below the cloud chamber within its isolating containment. Both instruments sample from the chamber volume through vertically arranged stainless steel tubes and cover the size range from $0.7-40 \mu \mathrm{m}(\mathrm{OPC} 1)$ and $2.3-104 \mu \mathrm{m}$ (OPC2). The number concentration and size of ice particles can also be retrieved from in situ infrared extinction measurements that are performed between 6000 and $800 \mathrm{~cm}^{-1}$ at $4 \mathrm{~cm}^{-1}$ resolution by coupling a FTIR spectrometer (IFS66v, Bruker) to an open-path multiple reflection cell inside the AIDA chamber (Wagner et al., 2006a). Moreover, the nucleation and growth of aspherical ice crystals is detected by light scattering and depolarisation measurements (Schnaiter et al., 2012). The instrument records the intensities of laser light of $488 \mathrm{~nm}$ wavelength that is scattered from the particles in the centre of the chamber in forward $\left(I_{\text {for }}\right.$, scattering angle $\left.2^{\circ}\right)$ and backward $\left(I_{\text {back}}\right.$, scattering angle $\left.178^{\circ}\right)$ direction. In the backward direction, the detected light intensity is polarisationresolved with $I_{\text {back,par }}$ and $I_{\text {back,per denoting the backscat- }}$ tered intensities parallel and perpendicular to the incident polarisation state of the laser light. The depolarisation ratio, $\delta$, is then defined as $\delta=I_{\text {back,per }} / I_{\text {back,par }}$. Apart from very small particles or particles with extreme aspect ratios, $\delta$ is different from zero for light scattering by aspherical particles (Mishchenko et al., 1996; Zakharova and Mishchenko, 2000). The formation of aspherical ice crystals by homogeneous freezing of liquid aqueous organic aerosol particles or by heterogeneous nucleation on glassy aqueous particles is therefore evidenced by an increase of the depolarisation ratio above the background level of about $0.02-0.03$ that is observed in the presence of spherical seed aerosol particles. The small background level results from Rayleigh scattering by air molecules and minor misalignments in the optical set-up. Furthermore, the laser has a finite polarisation ratio of about $100: 1$, leading to a small residual value for $I_{\text {back,per }}$ and thus the depolarisation ratio $\delta$.

\subsection{Aerosol generation and characterisation}

The investigated aerosol particles were generated from dilute aqueous solutions of four different solutes. We have prepared solutions of $3.5 \mathrm{wt} \%$ raffinose (D-(+)-raffinose pentahydrate, $\geq 98 \%$, Sigma-Aldrich), $3.0 \mathrm{wt} \%$ levoglucosan ((-)-1,6-anhydro-glucopyranose, $\geq 99 \%$, Merck Schuchardt), 3.0 wt \% HMMA (4-hydroxy-3-methoxy-DLmandelic acid, $98 \%$, Alfa Aesar), and $1.7 \mathrm{wt} \%$ raffinose $+1.7 \mathrm{wt} \%$ M5AS by dissolving the chemicals in purified water. M5AS corresponds to a mixture of $30.7 \mathrm{wt} \%$ malonic acid ( $\geq 99 \%$, Merck Schuchardt), $14.7 \mathrm{wt} \%$ malic acid (DL-malic acid, $\geq 99.5 \%$, Merck), $14.1 \mathrm{wt} \%$ maleic acid ( $\geq 99 \%$, Merck Schuchardt), $17.7 \mathrm{wt} \%$ glutaric acid ( $\geq 99 \%$, Merck Schuchardt), $7.4 \mathrm{wt} \%$ methylsuccinic acid (99\%, Sigma-Aldrich), and $15.4 \mathrm{wt} \%$ ammonium sulphate ( $\geq 99.5 \mathrm{wt} \%$, Merck). The solutions were filtered using a submicron syringe filter $(0.45 \mu \mathrm{m})$ to remove any undissolved particulates and were then injected into the AIDA chamber with a compressed-air atomiser (TSI, model 3076). Note that the solute weight fractions will strongly increase in the aerosol that is formed inside the AIDA chamber because the solution droplets, if injected above $T_{\mathrm{g}}$, will adjust to the ambient relative humidity. Aqueous raffinose solution droplets, e.g., have an equilibrium solute concentration of about $75 \mathrm{wt} \%$ when exposed to ice-saturated conditions at $246 \mathrm{~K}$ (Zobrist et al., 2008). The injection periods were adjusted to the designated experimental procedure. If repeated expansion runs with the same aerosol load or long cooling/heating periods of the AIDA chamber were intended, the initial number concentration was increased to account for the expected aerosol loss throughout the experiment. The number concentrations were measured with a condensation particle counter (CPC3010, TSI) and were initially in the range from $5000-15000 \mathrm{~cm}^{-3}$. The size distributions were measured with a scanning mobility particle sizer (SMPS, TSI) and an aerodynamic particle spectrometer (APS, TSI). The aerodynamic diameter of the APS was converted into a volume-equivalent sphere diameter, $d_{\mathrm{p}}$, assuming a particle density of $1.6 \mathrm{~g} \mathrm{~cm}^{-3}$. For spherical particles, the mobility-equivalent diameter of the SMPS is equal to $d_{\mathrm{p}}$ (Hinds, 1999).

Figure 3 shows two size distribution measurements of raffinose aerosol particles. The aqueous $3.5 \mathrm{wt} \%$ raffinose solution was sprayed into the AIDA vessel at $246 \mathrm{~K}$ (i.e., in the liquid regime above $T_{\mathrm{g}}$ ) and the chamber was then cooled to 
Table 1. Overview of the sequences of expansion runs conducted during five different experiments with glass-forming aqueous organic aerosol particles which are discussed in detail in the manuscript text. A specific expansion run will be referred to by combining the experiment number from the first column with the letter tabulated in the third column, e.g. run $1 \mathrm{~B}$, run $3 \mathrm{H}$, etc. The fourth and the fifth column denote the starting temperature and the type of the expansion run, respectively.

\begin{tabular}{|c|c|c|c|c|}
\hline Exp. No. & Solute & Run & $T / \mathrm{K}$ & Observations \\
\hline \multirow[t]{5}{*}{1} & HMMA & A & 247 & Droplet activation at $T>T_{\mathrm{g}}$ \\
\hline & & $\mathrm{B}$ & 221 & Heterogeneous ice nucleation at $T \ll T_{\mathrm{g}}$ \\
\hline & & $\mathrm{C}$ & 232 & Homogeneous freezing at $T<T_{\mathrm{g}}$ \\
\hline & & $\mathrm{D}$ & 232 & Pre-activation at $T<T_{\mathrm{g}}$ \\
\hline & & $\mathrm{E}$ & 247 & Droplet activation at $T>T_{\mathrm{g}}$ \\
\hline \multirow[t]{3}{*}{2} & Raffinose & A & 256 & Droplet activation at $T>T_{\mathrm{g}}$ \\
\hline & & B & 235 & Homogeneous freezing at $T<T_{\mathrm{g}}$ \\
\hline & & $\mathrm{C}$ & 224 & Pre-activation at $T<T_{\mathrm{g}}$ \\
\hline \multirow[t]{7}{*}{3} & Raffinose & A & 246 & Droplet activation at $T>T_{\mathrm{g}}$ \\
\hline & & $\mathrm{B}$ & 230 & Homogeneous freezing at $T<T_{\mathrm{g}}$ \\
\hline & & $\mathrm{C}-\mathrm{G}$ & 230 & $\begin{array}{l}\text { Pre-activation at } T<T_{\mathrm{g}} \text {; in each run, } \\
\text { the generated ice crystals were rapidly sublimed }\end{array}$ \\
\hline & & $\mathrm{H}$ & 230 & $\begin{array}{l}\text { First pre-activation, later on } \\
\text { homogeneous freezing at } T<T_{\mathrm{g}}\end{array}$ \\
\hline & & I & 230 & $\begin{array}{l}\text { Pre-activation at } T<T_{\mathrm{g}} \text {; in contrast to runs } \mathrm{C}-\mathrm{G} \text {, } \\
\text { the generated ice crystals were not sublimed }\end{array}$ \\
\hline & & $\mathrm{J}$ & 230 & Homogeneous freezing at $T<T_{\mathrm{g}}$ \\
\hline & & $\mathrm{K}$ & 230 & Pre-activation at $T<T_{\mathrm{g}}$ \\
\hline \multirow[t]{2}{*}{4} & Raff./M5AS & A & 216 & Homogeneous freezing at $T \approx T_{\mathrm{g}}$ \\
\hline & & B & 216 & Pre-activation at $T \approx T_{\mathrm{g}}$ \\
\hline \multirow[t]{2}{*}{5} & Raff./M5AS & A & 224 & Homogeneous freezing at $T>T_{\mathrm{g}}$ \\
\hline & & B & 216 & Homogeneous freezing at $T \approx T_{\mathrm{g}}$ \\
\hline
\end{tabular}

$230 \mathrm{~K}$, thereby entering the glassy regime (see Fig. 1). Trace a of Fig. 3 corresponds to freshly injected raffinose particles whereas trace $\mathrm{b}$ was recorded four hours later after cooling to $230 \mathrm{~K}$. Due to particle coagulation, the initial count median diameter of about $120 \mathrm{~nm}$ slightly increases to about $140 \mathrm{~nm}$ upon cooling. The size distributions are rather broad and extend up to a particle diameter of about $2 \mu \mathrm{m}$. Comparable size distributions were measured for the other solute species.

\section{Results and discussion}

Table 1 shows an overview of the sequences of expansion cooling cycles that were performed during five different experiments on the enhanced ice nucleation ability of ice cloud processed glassy aqueous aerosol particles. Since these experiments do not follow a standard procedure we will describe and analyse their outcome step by step. In order to introduce a typical experiment in which pre-activation was observed, we first present an example of two repetitive expansion runs conducted with HMMA aerosol particles in Sect. 4.1. In the following, particular experiments are described that shed light on further details and may help to elucidate the reason for the observed pre-activation behaviour. In Sect. 4.2, we present the results from two expansion experiments with raffinose aerosol particles featuring a long

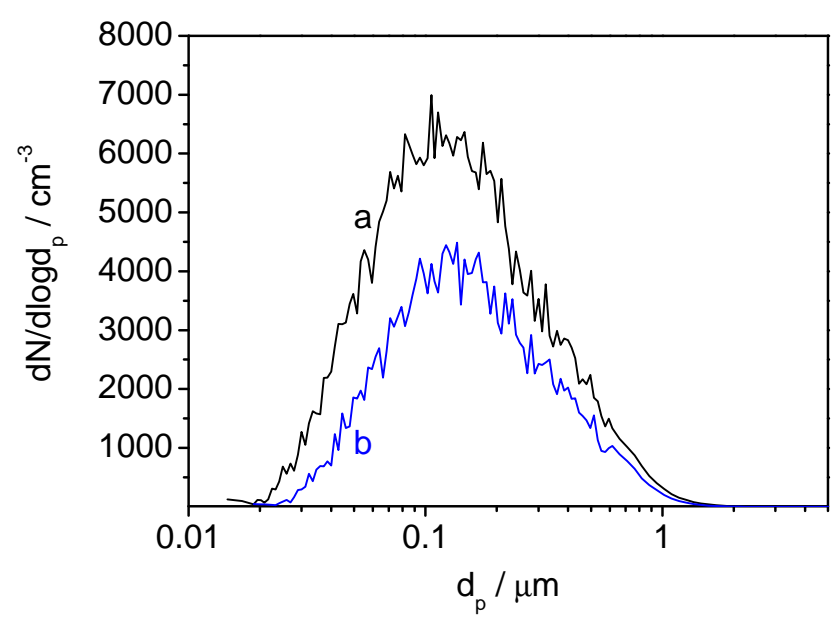

Fig. 3. Combined SMPS and APS number size distributions of aqueous raffinose particles after injection at $246 \mathrm{~K}$ (a) and subsequent cooling to $230 \mathrm{~K}$ (b).

time period of several hours between the initial homogeneous freezing run and the subsequent pre-activation run. In a further experiment, multiple expansion runs were conducted with raffinose aerosol particles in order to investigate whether the pre-activation behaviour might be lost in repeated ice nucleation runs (Sect. 4.3). Section 4.4 addresses 

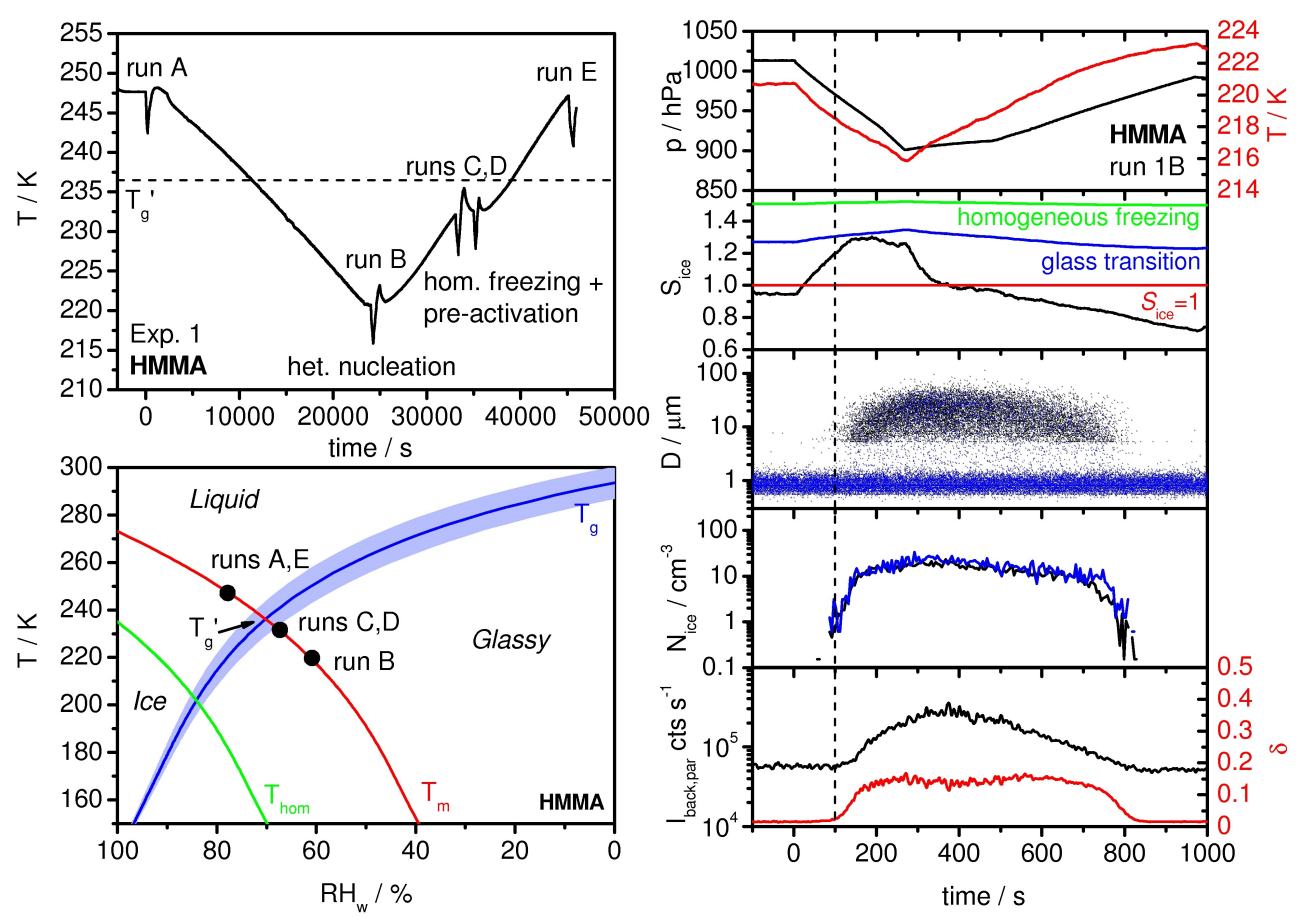

Fig. 4. Top left panel: Temporal evolution of the AIDA gas temperature during Exp. 1 with aqueous HMMA aerosol particles. Bottom left panel: Approximate starting points (black dots) of the experimental trajectories of the five expansion cooling cycles that were performed in the course of the experiment. As in Fig. 1, $T_{\mathrm{g}}$ denotes the glass transition temperature with the shaded blue area representing its uncertainty, $T_{\mathrm{m}}$ the ice melting temperature, and $T_{\text {hom }}$ the homogeneous freezing temperature. Right panel: Time series of various AIDA data during expansion run 1B. The five panels contain the following records: Panel 1: AIDA pressure (black line) and mean gas temperature (red line). Panel 2: Saturation ratio with respect to ice, $S_{\text {ice }}$ (black line), measured by TDL absorption. The additional coloured traces show the homogeneous freezing limit (green line), the glass transition curve (blue line), and the line for $S_{\text {ice }}=1$ (red line). Panel 3: Size of individual particles detected by the OPC1 (blue dots) and the OPC2 (black dots). Panel 4: Ice particle number concentration, $N_{\text {ice}}$, inferred from the OPC1 (blue line) and the OPC2 (black line). Panel 5: Backscattered intensity parallel to the incident polarisation state of the laser light, $I_{\text {back,par }}$ (black line), and backscattering linear depolarisation ratio, $\delta$ (red line). See text for details.

two pairs of repetitive expansion experiments with raffinose/M5AS aerosol particles which were started at temperatures around and above $T_{\mathrm{g}}^{\prime}$ in order to analyse whether the ice nucleation ability also changes in repeated expansion runs performed in the liquid regime above $T_{\mathrm{g}}^{\prime}$. We conclude this chapter with an overall discussion of our results in Sect. 4.5.

\subsection{A typical example of the pre-activation behaviour (HMMA, Exp. 1)}

For this introductory section, we have selected an experiment with HMMA which clearly illustrates the enhanced ice nucleation ability of ice cloud processed glassy aqueous aerosol particles. It also demonstrates the transition from heterogeneous nucleation at a temperature much lower than $T_{\mathrm{g}}^{\prime}$ to homogeneous nucleation at a temperature only slightly below $T_{\mathrm{g}}^{\prime}$ and then pre-activation in a subsequent expansion run started at the same temperature, underlining that the heterogeneous and the pre-activation behaviour are different. The top left panel of Fig. 4 shows the overall time series of the AIDA gas temperature during the experiment. The HMMA aerosol particles were injected at a temperature of $247 \mathrm{~K}$, i.e., in the liquid regime above $T_{\mathrm{g}}^{\prime}$, as can be seen in the phase diagram shown in the bottom left panel. This phase diagram also shows the approximate starting points of the subsequent expansion runs in terms of the ambient relative humidity (see related discussion of Fig. 1 in Sect. 2). After a droplet activation run at $247 \mathrm{~K}$ in the liquid regime (run 1A) where homogeneous freezing cannot occur, the chamber was cooled overnight to $221 \mathrm{~K}$ and run $1 \mathrm{~B}$ was performed to study heterogeneous ice nucleation on the glassy aqueous HMMA particles. Afterwards, the chamber was warmed to $232 \mathrm{~K}$. A pair of expansion runs (runs 1C and 1D) were conducted at the elevated temperature to investigate the pre-activation behaviour before the chamber temperature was further raised to $247 \mathrm{~K}$ for a final droplet activation run back up in the liquid regime (run 1E).

The right panel of Fig. 4 shows time series of various AIDA data for run 1B which are arranged as follows. In the first row, the traces of the AIDA pressure (black line) and the mean AIDA gas temperature (red line) are plotted. The second row shows the time series of the saturation ratio with 
respect to ice, $S_{\text {ice }}$ (black line), from the TDL absorption measurements. Applying the same colour code as in Fig. 1 and in the bottom left panel of Fig. 4, the additional traces show the critical ice saturation ratio for homogeneous freezing (Koop et al., 2000), the glass transition curve (Zobrist et al., 2008), as well as the line for $S_{\text {ice }}=1$. Scatter plots from the two optical particle counters OPC1 (blue dots) and OPC2 (black dots) are shown in the third row. Each dot denotes a single particle count event classified into one of the OPCs' size channels. Whereas the OPC2 only quantitatively detects the large ice crystals which nucleate in the course of the expansion run, the OPC 1 is additionally sensitive to the large-diameter tail of the size distribution of the glassy seed aerosol particles extending up to a diameter of about $2 \mu \mathrm{m}$ (Fig. 3). To infer the ice particle number concentration, $N_{\text {ice, }}$, of the nucleation event from the OPC1, an optical threshold size is introduced to cut off the interstitial aerosol particles whereas, for the OPC2, $N_{\text {ice }}$ equals the total particle count rate. Employing the same colour code as in the third panel, panel four shows the time of evolution of $N_{\text {ice }}$ deduced from the two OPCs. The fifth panel shows two records from the in situ laser light scattering and depolarisation measurements, namely the traces of the backscattered intensity parallel to the incident polarisation state of the laser light, $I_{\text {back,par }}$ (black line), and the linear backscattering depolarisation ratio, $\delta$ (red line). Time zero denotes the start of pumping during the expansion cycle and does not correspond to the overall experiment time plotted in top left panel of Fig. 4.

In spite of the ice-covered chamber walls, the expansion run is started at slightly ice-subsaturated conditions with $S_{\text {ice }}=0.94$. This is because the gas temperature is always a few tenths of a Kelvin higher than the wall temperature due to some internal heat sources, including the mixing fan, heated sampling and inlet tubes, and heating foils to prevent the mirrors of the internal multiple reflection cells from icing. The vertical dashed line indicates the onset of ice nucleation during the expansion at an ice saturation ratio of $S_{\text {ice }}=1.20$. Ice nucleation initiates clearly before reaching the homogeneous freezing threshold and is due to heterogeneous nucleation on the glassy seed aerosol particles (Table A1). The detected nucleated ice crystals appear as points in the scatter plot of the OPCs at optical diameters larger than $5 \mu \mathrm{m}$ and provoke an increase in the backscattered intensity $I_{\text {back,par }}$. Also, $\delta$ increases from its background value of 0.02 observed for the spherical, interstitial seed aerosol particles to a maximum value of about 0.16 . Pumping is continued for another $200 \mathrm{~s}$ after the onset of ice nucleation, leading to a further increase in $S_{\text {ice }}$ to a maximum value of 1.29. As apparent from the second panel, the experimental trajectory does not cross the glass transition curve during the expansion cycle. The maximum number concentration of the nucleated ice crystals amounts to $25 \mathrm{~cm}^{-3}$. After a deliberately short observation time of only about $200 \mathrm{~s}$, the chamber is refilled with dry synthetic air to ambient pressure to rapidly sublime the generated ice cloud. This was done to avoid sedimen- tation of the nucleated ice crystals together with their seed aerosol particles to ensure that a proportion of those particles that have promoted ice nucleation in run $1 \mathrm{~B}$ at $221 \mathrm{~K}$ are still present at the start of expansion run $1 \mathrm{C}$ after the chamber has been warmed to $232 \mathrm{~K}$. After all ice crystals have sublimed, both traces from the laser light scattering measurements regain their initial values from before the start of pumping.

Figure 5 compares the time series of the AIDA data from the two expansion cycles which both started at $232 \mathrm{~K}$ (runs 1C and 1D). Shortly after the start of run 1C (left panel), the experimental trajectory crosses the glass transition curve because the starting temperature was only slightly below $T_{\mathrm{g}}^{\prime}$. The main ice nucleation event during the expansion run, as again indicated by the vertical dashed line, occurs about 180 $\mathrm{s}$ after crossing $\mathrm{RH}_{\mathrm{g}}$ and represents a typical, sharp nucleation mode due to homogeneous freezing. The critical ice saturation ratio at the onset of ice formation is $1.38 \pm 0.07$ which is slightly below the homogeneous freezing limit predicted by Koop et al. (2000). We have observed a similar discrepancy in recent ice nucleation experiments with aqueous sulphuric acid and sodium chloride solution droplets which also homogeneously froze at a threshold of $S_{\text {ice }}=1.38-1.39$ at temperatures around $230 \mathrm{~K}$ (Wagner et al., 2008; Wagner et al., 2011). We will address this issue in a forthcoming manuscript. For the present study, it is important to note that the ice nucleation behaviour of the aqueous HMMA particles in run $1 \mathrm{C}$ is equivalent to aqueous inorganic solution droplets which are initially not in a glassy state. We cannot state whether there still exist concentration gradients within the aqueous HMMA particles at the onset of ice nucleation, i.e., whether the particle core might still be in a glassy or highly viscous state. But at least the outer particle layers must have returned to equilibrium conditions with respect to the ambient relative humidity as evidenced by the identical freezing threshold compared to inorganic aqueous solution droplets.

Before the homogeneous freezing limit is reached in run $1 \mathrm{C}$, only very few seed aerosol particles have nucleated ice heterogeneously, yielding $N_{\text {ice }}$ of about $0.5 \mathrm{~cm}^{-3}$. Note that these ice crystals nevertheless cause a clear increase in the depolarisation ratio $\delta$, pointing to the sensitivity of this method when detecting small numbers of large, nonspherical particles. Ice nucleation on background aerosol particles might contribute to this minor heterogeneous mode. The dominant heterogeneous mode observed during run $1 \mathrm{~B}$ is clearly absent at the elevated temperature in run $1 \mathrm{C}$. Obviously, the glassy HMMA particles have liquefied before being able to act as heterogeneous ice nuclei in the expansion run started at $232 \mathrm{~K}$.

About $170 \mathrm{~cm}^{-3}$ ice crystals are formed by homogeneous freezing during run $1 \mathrm{C}$. In order to finally cross the homogeneous freezing threshold, we had to increase the pumping speed because $S_{\text {ice }}$ had started to level off at the lower cooling rate that was employed before (see pressure profile in the top panel). Due to the large number of ice crystals, 

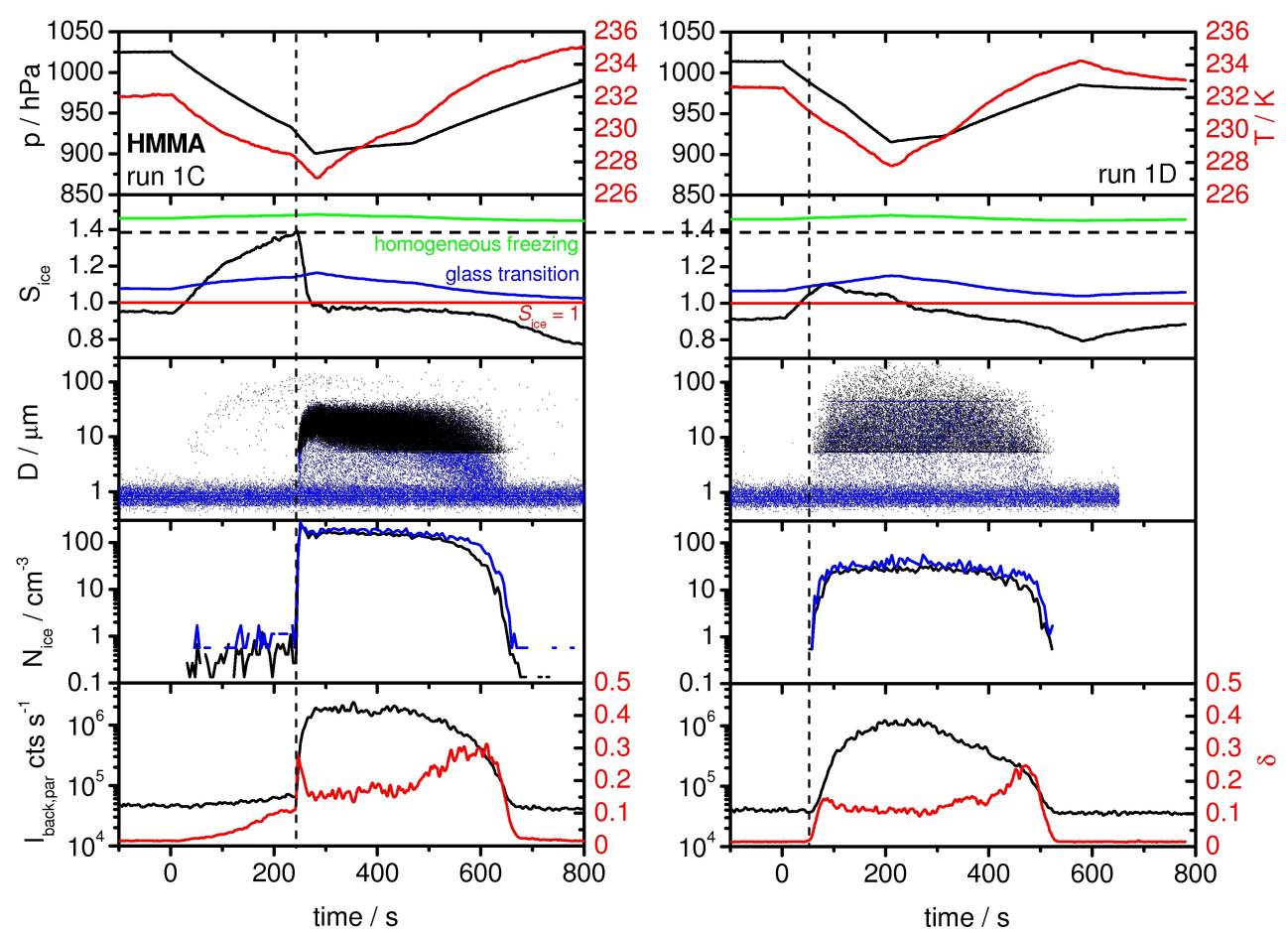

Fig. 5. Time series of various AIDA records during expansion runs 1C and 1D with HMMA. The individual panels contain the same measurements as in the right panel of Fig. 4. To facilitate the comparison between the two expansion cycles, all y-axes of adjacent panels are identically scaled. The horizontal dashed line in the second row panels denotes the homogeneous freezing limit observed in run $1 \mathrm{C}$.

the supersaturation with respect to ice is rapidly depleted. At $30 \mathrm{~s}$ after the onset of ice nucleation, the ice saturation ratio dropped back to $S_{\text {ice }}=1$, and it took only 20 s to fall below the glass transition curve. This means that the freezeconcentrated HMMA solution that was rejected from the ice lattice rapidly re-enters the glassy regime and again vitrifies as already discussed in Sect. 2. About $200 \mathrm{~s}$ after the end of pumping, the nucleated ice crystals were sublimed by re-filling the AIDA chamber to ambient pressure. During re-filling, $S_{\text {ice }}$ temporarily dropped to a minimum value of about 0.72. After reaching ambient pressure, a period of about 15 min was necessary to restore the values of the gas temperature and the ice saturation ratio to those prevalent at the beginning of run $1 \mathrm{C}$. Then, $32 \mathrm{~min}$ after starting run $1 \mathrm{C}$, the same aerosol load was again probed on its ice nucleation behaviour in run 1D under the same conditions as 1C.

The AIDA data of run 1D shown in the right part of Fig. 5 reveal an entirely different ice nucleation behaviour compared to run $1 \mathrm{C}$. Starting at a threshold of only $S_{\text {ice }}=1.05$, a dominant ice crystal mode with $N_{\text {ice }}=30 \mathrm{~cm}^{-3}$ is formed that was absent in run $1 \mathrm{C}$. We call this the pre-activation behaviour of ice cloud processed glassy aqueous aerosol particles because it is only observed after a preceding homogeneous freezing run. Throughout the experiment $1 \mathrm{D}, S_{\text {ice }}$ stays far below the homogeneous freezing threshold from run 1C (as marked by the horizontal dashed line) and also does not cross the glass transition curve. The ice cloud was then again deliberately sublimed shortly after its formation to conserve the seed aerosols that have promoted ice nucleation in run 1D also for run 1E. This final expansion run was performed in the liquid regime after the AIDA chamber was warmed to $247 \mathrm{~K}$ and its records are shown in Fig. 6. Run $1 \mathrm{E}$ is started at a comparatively low ice saturation ratio of only 0.8 which approximately overlaps with the glass transition curve. This is because the repeated cloud expansion runs during the experiment have depleted the ice coverage of the inner chamber walls. It therefore took about $100 \mathrm{~s}$ of expansion cooling before ice-supersaturated conditions had been established in the chamber. The pre-activation behaviour that was evident in run $1 \mathrm{D}$ is no longer visible in run $1 \mathrm{E}$. Less than $0.1 \mathrm{~cm}^{-3}$ ice particles, nonetheless causing a very small increase in $\delta$ between 200 and $350 \mathrm{~s}$, are heterogeneously formed so that the panel showing $N_{\text {ice }}$ is omitted. The cloud that is formed at about $t=340 \mathrm{~s}$ (vertical dashed line) is composed of liquid water because saturation with respect to supercooled water has been surpassed during continued pumping and the HMMA particles were activated to micron-sized water droplets with an upper diameter of about $5 \mu \mathrm{m}$. With the formation of the dense cloud of large spherical water droplets, $\delta$ is no longer sensitive to the very small number of aspherical ice crystals and, therefore, drops back to its background value. Pumping is stopped at a temperature of $241 \mathrm{~K}$, i.e., before the homogeneous freezing temperature of pure water droplets at $236 \mathrm{~K}$ was reached. The cloud 


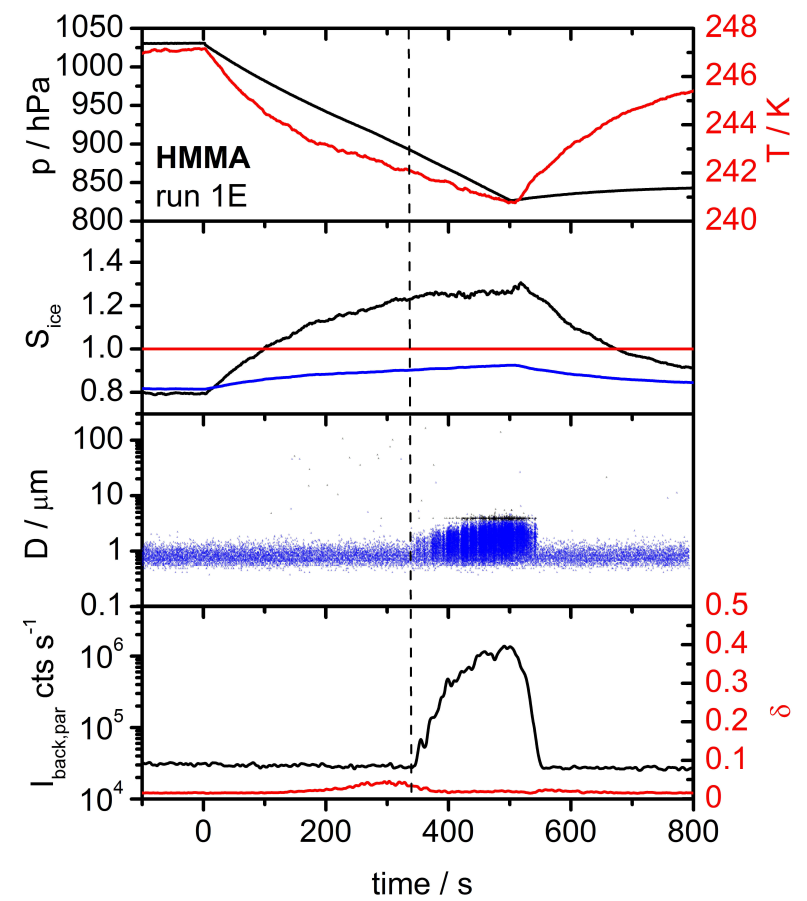

Fig. 6. Time series of various AIDA records during expansion run 1E with HMMA. Compared to the right part of Fig. 4, the fourth panel showing $N_{\text {ice }}$ is omitted because only a negligible number concentration of ice particles has been formed. Otherwise, the same measurements are shown.

droplets rapidly evaporate when the relative humidity starts to drop below water saturation.

After introducing the basic observations of the preactivation behaviour in this section, we present additional examples in the following sections where different experimental procedures allow for answering further questions concerning the modified ice nucleation ability of the glassy particles. The above experiment with HMMA was specifically designed to study both heterogeneous nucleation and preactivation behaviour after having become aware of the latter from preceding experiments. When investigating the preactivation behaviour, the two repetitive expansion runs, i.e., the homogeneous freezing run followed by the pre-activation run, were usually performed in immediate succession at an interval of about half an hour. In Sect. 4.2, we answer the question whether the pre-activation behaviour can also be observed when there is a much longer time period between the two expansion cycles.

\subsection{Is the pre-activation behaviour conserved for long time periods at ice-subsaturated conditions? (Raffinose, Exp. 2)}

The top panel of Fig. 7 shows the temperature profile of Exp. 2 with aqueous raffinose aerosol particles. It was our first experiment conducted with this substance and was originally
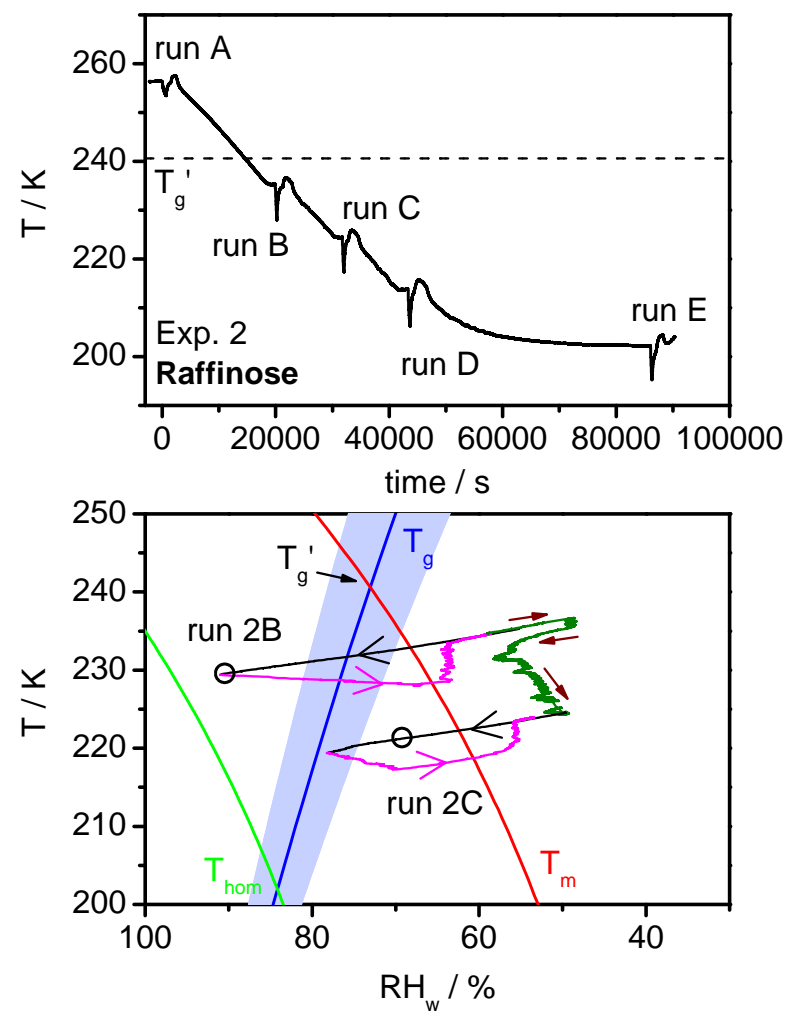

Fig. 7. Top panel: Temporal evolution of the AIDA gas temperature during Exp. 2 with aqueous raffinose aerosol particles. Bottom panel: Experimental trajectories of expansion runs $2 \mathrm{~B}$ and $2 \mathrm{C}$ as a function of $\mathrm{RH}_{\mathrm{W}}$ (see also Fig. 1). Different colours and arrows are used to underline the temporal order of the experiment, as described in detail in the text. The circles denote the onsets of ice nucleation during the expansion runs, whose further AIDA records are shown in Fig. 8.

aimed at investigating the temperature dependence of heterogeneous ice nucleation on glassy aerosol particles over a more extended temperature range than possible with citric acid due to the much higher $T_{\mathrm{g}}^{\prime}$ temperature of raffinose. The dilute aqueous raffinose solution was sprayed into the AIDA chamber with the atomiser at a temperature of $256 \mathrm{~K}$, i.e., as in Exp. 1 with HMMA in the liquid regime above $T_{\mathrm{g}}^{\prime}$. After a droplet activation run in the liquid regime (run $2 \mathrm{~A}$ ), the AIDA chamber was cooled to $235 \mathrm{~K}$ for the first ice nucleation run below $T_{\mathrm{g}}^{\prime}$ (run 2B). The chamber was then further cooled in steps of about $10 \mathrm{~K}$ for three additional expansion runs (runs 2C, 2D, and 2E). In the lower panel of Fig. 7, the experimental trajectories of expansion runs $2 \mathrm{~B}$ and $2 \mathrm{C}$ are plotted as a function of the $\mathrm{RH}_{\mathrm{w}}$. Different colours are used to illustrate the temporal order of the trajectory. The black parts denote the time periods from the start of pumping until reaching the maximum ice saturation ratios during the expansions. The onsets of ice nucleation in the two experiments are marked by black circles. The time periods after reaching the maximum ice saturation ratios until refilling the AIDA 

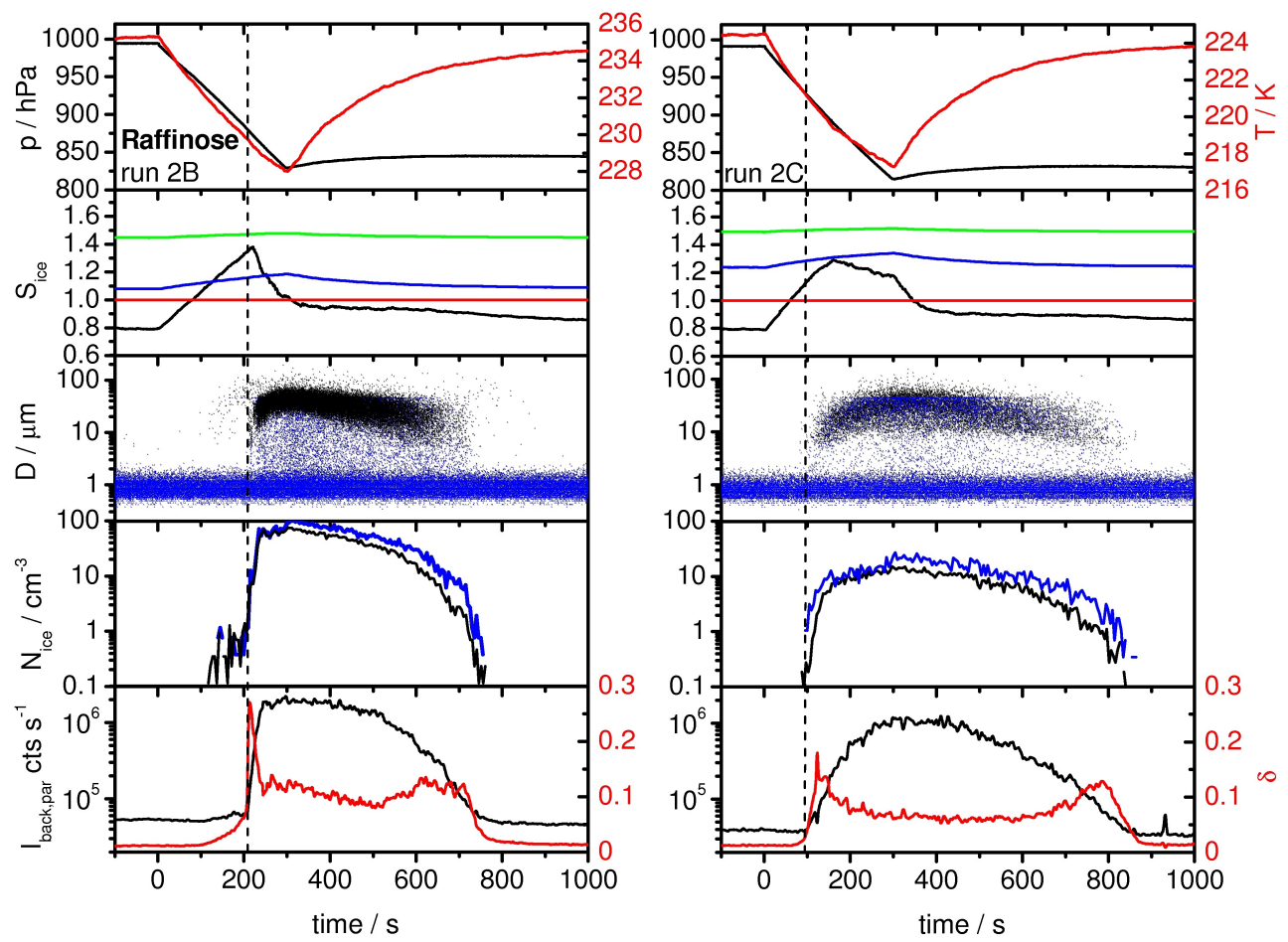

Fig. 8. Time series of various AIDA records during expansion runs $2 \mathrm{~B}$ and $2 \mathrm{C}$ with raffinose. The individual panels contain the same measurements as in Fig. 5.

chamber with synthetic air to ambient pressure are plotted in magenta. The olive-green part denotes the temporal evolution of the relative humidity during refilling the AIDA chamber to ambient pressure after the ice cloud from run 2B had sublimed and during the subsequent cooling period of the aerosol vessel to $224 \mathrm{~K}$, the starting temperature of run $2 \mathrm{C}$. Run $2 \mathrm{C}$ was started 200 min after run $2 \mathrm{~B}$. The AIDA records from the two expansion runs are shown in the customary format in Fig. 8.

Run 2B represents a typical homogenous freezing event as in run $1 \mathrm{C}$ with HMMA. The few ice crystals $\left(N_{\text {ice }}\right.$ about $0.5 \mathrm{~cm}^{-3}$ ) which are formed before the homogeneous freezing threshold (vertical dashed line in the left part of Fig. 8) is surpassed can be attributed to nucleation on background aerosol particles. As discussed before, the nucleation threshold is slightly below the relative humidity predicted by Koop et al. (2000). The subsequent expansion run 2C shows early ice nucleation at $S_{\text {ice }}=1.12$ due to pre-activation of the glassy aerosol particles by the preceding ice cloud formation. The peak ice saturation ratio stays below the glass transition curve and, as in the pre-activation run with HMMA, the number concentration of nucleated ice crystals is smaller than in the homogeneous freezing run. We initially interpreted this behaviour as heterogeneous ice nucleation on the glassy aqueous raffinose aerosol particles as previously observed for citric acid, being surprised at the sharp transition between homogeneous freezing $(235 \mathrm{~K})$ and what looked like dominant heterogeneous ice nucleation ability $(224 \mathrm{~K})$ within a temperature range of only $11 \mathrm{~K}$. Later, we learned from a different experiment that early ice formation was absent and only homogeneous freezing occurred when the raffinose aerosol particles were directly probed at $224 \mathrm{~K}$ without performing the intermediate expansion run at $235 \mathrm{~K}$, realising that the pair of expansion runs shown in Fig. 8 were our first observation of the pre-activation behaviour. Heterogeneous ice nucleation on glassy aqueous raffinose particles in the deposition mode only occurs below a threshold temperature of about $215 \mathrm{~K}$ and requires a higher ice saturation threshold than observed in run $2 \mathrm{C}$ (Table $\mathrm{A} 1$ ).

During re-filling and cooling the AIDA chamber between the expansion runs $2 \mathrm{~B}$ and $2 \mathrm{C}$, the ice cloud processed aerosol particles from run $2 \mathrm{~B}$ were exposed for more than two and a half hours to an ice saturation ratio between 0.7 (minimum during re-filling period) and 0.8 (after re-filling and temperature equilibration). The comparatively low value for $S_{\text {ice }}$ after temperature equilibration might be due to incomplete ice coverage of the chamber walls in this particular experiment. Although the ice nucleation threshold in run $2 \mathrm{C}$ with Raffinose $\left(S_{\text {ice }}=1.12\right)$ is slightly higher than in run 1D with HMMA ( $S_{\text {ice }}=1.05$, conducted only $32 \mathrm{~min}$ after the homogeneous freezing run), the results presented in this section clearly indicate that the pre-activation behaviour of ice cloud processed glassy aerosol is conserved even if the 
particles are subjected to an ice-subsaturated environment for at least $2.5 \mathrm{~h}$.

The results from the two succeeding expansion runs 2D and $2 \mathrm{E}$ are difficult to interpret and are therefore not shown. It would be interesting to analyse whether the pre-activation behaviour from run $2 \mathrm{C}$ is still observable when the same aerosol load is probed again in run $2 \mathrm{D}$. The starting temperature of run 2D, however, is already below the threshold of $215 \mathrm{~K}$ where heterogeneous ice nucleation on glassy aqueous raffinose particles can also be detected (Table A1). In order to unambiguously investigate how the pre-activation behaviour evolves when the glassy aerosol is probed in further expansion cycles after the initial pre-activation run, we have performed a dedicated experiment with raffinose at a constant temperature of $230 \mathrm{~K}$, the results of which are discussed in the next section. One of the questions that we want to answer is whether the pre-activation behaviour is lost if the aerosol is at least temporarily exposed to a relative humidity above the glass transition during the expansion. This would require that the trace for $S_{\text {ice }}$ crosses the $\mathrm{RH}_{\mathrm{g}}$ curve during the expansion, which was not the case in the pre-activation runs presented so far (see right parts of Figs. 5 and 8).

\subsection{Is the pre-activation behaviour lost in multiple expansion runs? (Raffinose, Exp. 3)}

The upper panel of Fig. 9 shows the AIDA gas temperature in the course of Exp. 3 where aqueous glassy raffinose particles were probed in a series of altogether 10 repetitive expansion runs at $230 \mathrm{~K}$. In order to be able to perform the entire experiment on a single measurement day, the injection temperature was reduced compared to Exp. 2 (245.5 K versus $256 \mathrm{~K}$ in Exp. 2). After a droplet activation run (run $3 \mathrm{~A})$ above the homogeneous freezing temperature without ice formation, the chamber was cooled to $230 \mathrm{~K}$ for the series of expansion runs 3B-3K. As explained in Sect. 4.2, this temperature was chosen to enter a regime in the state diagram where the pre-activation behaviour could be studied without interference from heterogeneous ice nucleation on the glassy raffinose aerosol particles. The AIDA records from the series of expansion runs are arranged in two figures, with Fig. 10 showing the data for runs $3 \mathrm{~B}-3 \mathrm{H}$ and Fig. 11 those for runs $3 \mathrm{H}-3 \mathrm{~K}$. The modification of the ice nucleation ability in the course of the pre-activation runs $3 \mathrm{C}-3 \mathrm{H}$ is summarised in the lower panel of Fig. 9, showing the number concentration of nucleated ice crystals as a function of the ice supersaturation.

The expansion runs $3 \mathrm{~B}$ and $3 \mathrm{C}$ represent a typical pair of homogeneous freezing and pre-activation runs, respectively. The AIDA records shown in Fig. 10 reveal a homogeneous freezing mode with $N_{\text {ice }}$ of about $100 \mathrm{~cm}^{-3}$ in run 3B, followed by an early pre-activation mode with $N_{\text {ice }}=35 \mathrm{~cm}^{-3}$ in run 3C. As usual, the homogeneous freezing threshold is slightly below the prediction by Koop et al. (2000), and the pre-activation mode starts to form at $S_{\text {ice }} \approx 1.05$. Background aerosol might be responsible for the small het-
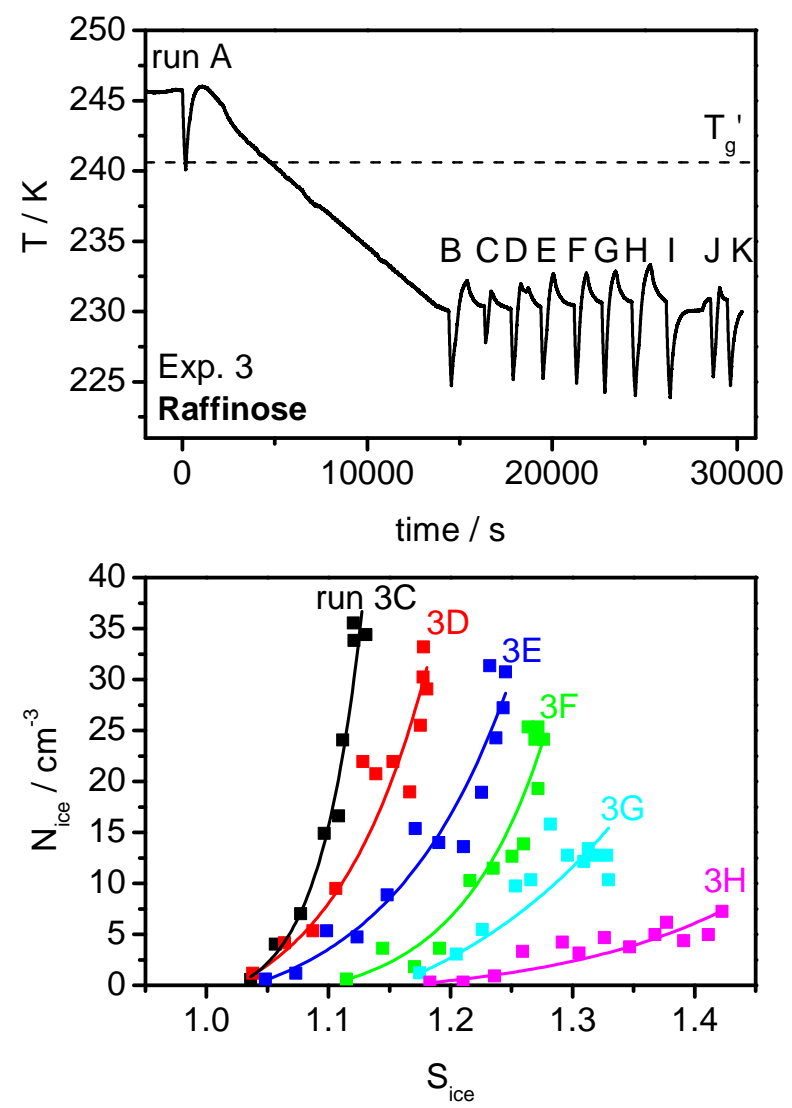

Fig. 9. Top panel: Temporal evolution of the AIDA gas temperature during Exp. 3 with aqueous raffinose aerosol particles. Bottom panel: Number concentration of nucleated ice crystals, $N_{\text {ice }}$, as a function of the supersaturation with respect to ice, $S_{\text {ice}}$, during the expansion runs $3 \mathrm{C}-3 \mathrm{H}$ (squares). For run $3 \mathrm{H}$, only the data of the pre-activation but not the subsequent homogeneous freezing mode are included. The data were fitted by an exponential approximation as described in Möhler et al. (2006). Each individual trace covers the time period from the nucleation onset until reaching the maximum ice particle number concentration during the expansion run.

erogeneous ice mode with $N_{\text {ice }}<1 \mathrm{~cm}^{-3}$ that is observed in run $3 \mathrm{~B}$ before the homogeneous freezing threshold is reached. First of all, we wanted to investigate whether the pre-activation behaviour is conserved in a further expansion cycle when the experimental trajectory has remained in the glassy regime. In run 3C, pumping was therefore stopped shortly after ice formation in order to keep $S_{\text {ice }}$ below the glass transition relative humidity. The ice cloud in run $3 \mathrm{C}$ was then rapidly sublimed by refilling the AIDA chamber to ambient pressure in order to avoid sedimentation of the seed aerosols that promoted ice nucleation in this first preactivation run. In the subsequent expansion run $3 \mathrm{D}$, the ice nucleation behaviour of the aerosol load remained indeed unchanged compared to run $3 \mathrm{C}$, i.e., the pre-activated particles did not lose their enhanced ice nucleation ability when probed again in a second pre-activation run. Pumping was 


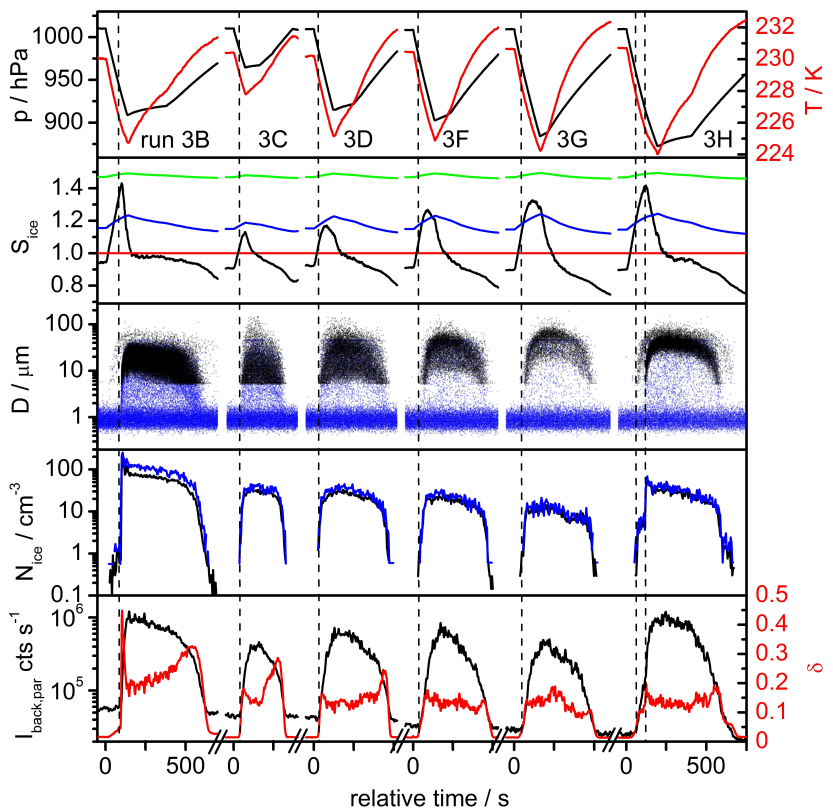

Fig. 10. Time series of various AIDA records during expansion runs $3 \mathrm{~B}, 3 \mathrm{C}, 3 \mathrm{D}, 3 \mathrm{~F}, 3 \mathrm{G}$, and $3 \mathrm{H}$ with raffinose. The individual panels contain the same measurements as in Fig. 5. In each expansion run, time zero denotes the start of pumping and does not refer to the overall time scale of the experiment shown in Fig. 9. The time periods between the expansion runs for re-establishing equilibrium conditions in terms of temperature and relative humidity are omitted.

deliberately continued for a longer time period in run 3D in order to now cross the glass transition curve during the expansion and to investigate the associated effect on the preactivation behaviour. The trace of $S_{\text {ice }}$ in the second row of Fig. 10 shows that the peak ice saturation ratio in run $3 \mathrm{D}$ has increased compared to run $3 \mathrm{C}$ but has remained below the glass transition relative humidity (blue trace) because the supersaturation was still efficiently quenched by the large number of nucleated ice crystals. Another intermediate preactivation cycle (run 3E, data not shown) had to be performed before the ice saturation ratio first exceeded the glass transition curve in the course of expansion run $3 \mathrm{~F}$.

In each of the pre-activation runs $3 \mathrm{C}-3 \mathrm{E}$, a small fraction of ice crystals which have nucleated first on the most ice-active seed aerosol particles were lost due to continued pumping and sedimentation. In comparison with the initial pre-activation run $3 \mathrm{C}$, the nucleation threshold in run $3 \mathrm{~F}$ has therefore slightly increased to $S_{\text {ice }} \approx 1.08$ and the number concentration of nucleated ice crystals has decreased to $N_{\text {ice }}=25 \mathrm{~cm}^{-3}$. Note that the precision of the TDL water vapour measurements is much better than $1 \%$ at a temperature of $230 \mathrm{~K}$ so that small relative changes of $S_{\text {ice }}$ in consecutive expansion runs can indeed be resolved. As a smaller number concentration of ice crystals less efficiently quenches the supersaturation in the course of expansion cooling, the peak ice saturation ratio gradually increases between run $3 \mathrm{C}$

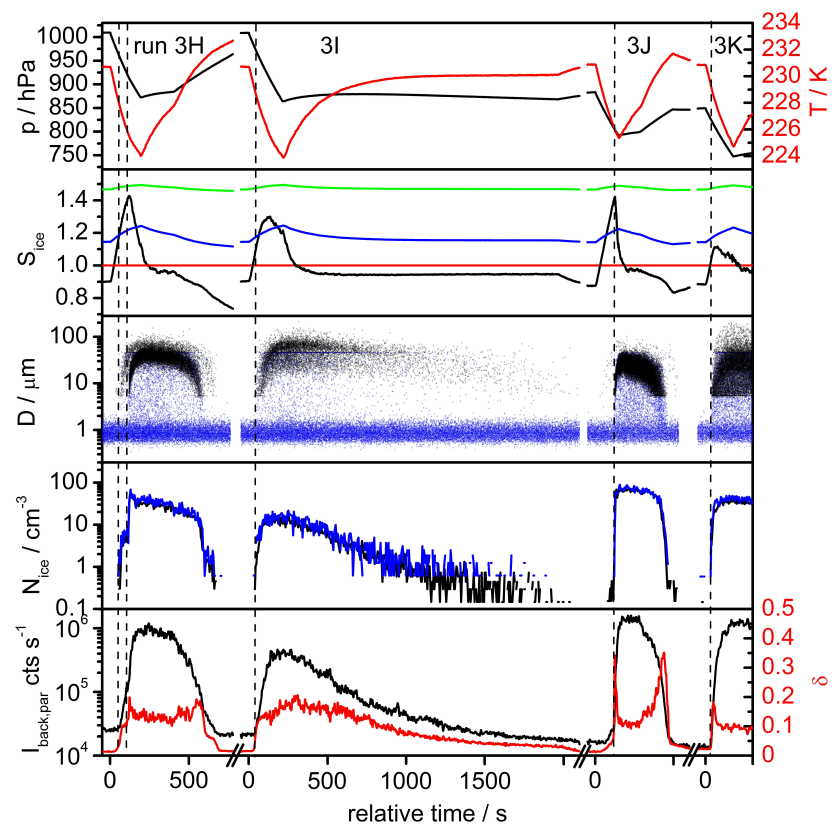

Fig. 11. Time series of various AIDA records during expansion runs $3 \mathrm{H}, 3 \mathrm{I}, 3 \mathrm{~J}$, and $3 \mathrm{~K}$ with raffinose. The individual panels contain the same measurements as in Fig. 5.

and run $3 \mathrm{~F}$ and for a time period of about one minute, $S_{\text {ice }}$ has crossed the glass transition relative humidity during run $3 \mathrm{~F}$. The succeeding expansion run $3 \mathrm{G}$ still shows early ice formation with an onset at $S_{\text {ice }}=1.14$ and $N_{\text {ice }}=12 \mathrm{~cm}^{-3}$. The decrease in $N_{\text {ice }}$ and the increase in the threshold ice saturation ratio between runs $3 \mathrm{~F}$ and $3 \mathrm{G}$ are somewhat more pronounced compared to the smooth change in these quantities within the four preceding pre-activation runs 3C-3F (Fig. 9, bottom panel). This may indicate that the pre-activation behaviour was indeed affected by the modified experimental trajectory in run $3 \mathrm{~F}$ where $S_{\text {ice }}$ has temporarily entered the liquid regime above $\mathrm{RH}_{\mathrm{g}}$. We will further address this issue in the overall discussion in Sect. 4.5.

During run 3G, the $S_{\text {ice }}$ trajectory has remained in the liquid regime above the glass transition relative humidity for about two minutes. In the next expansion cycle $3 \mathrm{H}$ (last expansion run shown in Fig. 10), the onset of the pre-activation mode has further increased to $S_{\text {ice }}=1.18$ and the number concentration of ice crystals has decreased by another $50 \%$ compared to run $3 \mathrm{G}$, yielding $N_{\text {ice }}=6 \mathrm{~cm}^{-3}$. During continued pumping, the supersaturation with respect to ice exceeds the homogeneous freezing threshold, leading to an additional ice particle mode with $N_{\text {ice }}=40 \mathrm{~cm}^{-3}$. The AIDA records of run $3 \mathrm{H}$ are again plotted in the left part of Fig. 11 as a benchmark for the ice nucleation ability that is revealed in the final three expansion runs $3 \mathrm{I}-3 \mathrm{~K}$. In run $3 \mathrm{I}$, the preceding homogeneous freezing event from run $3 \mathrm{H}$ again reinforces the preactivation behaviour, leading to ice formation at $S_{\text {ice }}=1.05$ with $N_{\text {ice }}=15 \mathrm{~cm}^{-3}$. The AIDA data from run 3I are shown 

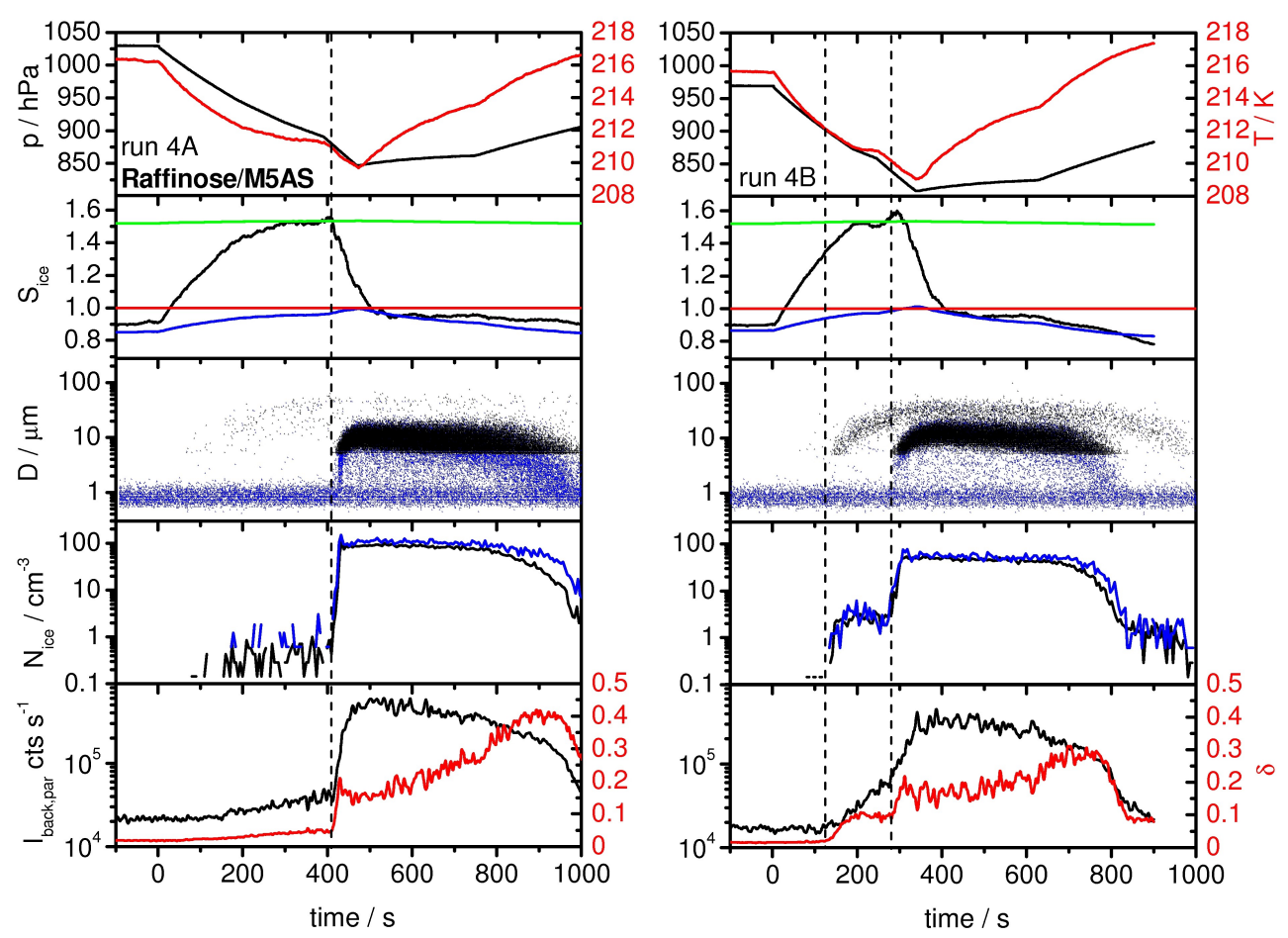

Fig. 12. Time series of various AIDA records during expansion runs $4 \mathrm{~A}$ and $4 \mathrm{~B}$ with raffinose/M5AS aerosol particles. The individual panels contain the same measurements as in Fig. 5.

for a longer time period because, instead of rapidly subliming the generated ice cloud, the chamber was kept at reduced pressure to wait for the sedimentation of the ice crystals and their associated seed aerosol particles. In the subsequent expansion run $3 \mathrm{~J}$, early ice formation due to pre-activation is completely absent and only the homogeneous freezing mode can be observed. This confirms that the pre-activation behaviour is not a property of the entire aerosol population but is only related to those seed particles which have nucleated ice in the preceding homogeneous freezing cycle. Once these pre-activated seed aerosol particles are lost by sedimentation, the remaining aerosol load again only promotes ice formation by homogeneous freezing. In the final expansion run $3 \mathrm{~K}$ the pre-activation behaviour is again dominant, leading to early ice nucleation at $S_{\text {ice }}=1.05$.

In the following section, after having presented three experiments with substances that feature a comparatively high $T_{\mathrm{g}}^{\prime}$ temperature, we turn our attention to experiments with the raffinose/M5AS mixture that has a $T_{\mathrm{g}}^{\prime}$ temperature of about $210 \mathrm{~K}$. We will show that the pre-activation behaviour is also evident in repetitive expansion runs conducted with raffinose/M5AS aerosol particles and describe an important reference experiment to answer the question whether the initial homogeneous freezing cycle must indeed be performed in the glassy regime to induce the pre-activation behaviour in the subsequent expansion run. For HMMA and raffinose, the chamber temperature would have to be raised above the homogeneous freezing temperature of pure water droplets to clearly enter the liquid regime and such a control experiment is not feasible. For the raffinose/M5AS mixture, a pair of repetitive expansion runs can be conducted at an intermediate temperature above $T_{\mathrm{g}}^{\prime}$ but below the homogeneous freezing temperature of supercooled water droplets to investigate whether homogeneous freezing of aqueous liquid raffinose/M5AS solution droplets also leads to an enhanced ice nucleation ability in the subsequent expansion cycle.

\subsection{Is the pre-activation behaviour absent in repetitive expansion runs started above $T_{\mathrm{g}}^{\prime}$ ? (Raffinose/M5AS, Exps. 4 and 5)}

To answer the above question, we compare the AIDA data from two different pairs of repetitive expansion runs conducted with raffinose/M5AS aerosol particles (Exps. 4 and 5). Before discussing them in detail, we want to highlight the differences in experimental procedure in each case: The first expansion run in Exp. 4 was started at an ice saturation ratio close to the glass transition relative humidity, $\mathrm{RH}_{\mathrm{g}}$, thus the aerosol particles were ultra-viscous or glassy. In contrast, the first expansion run in Exp. 5 was started in the liquid regime well above $\mathrm{RH}_{\mathrm{g}}$. How this difference affects the ice nucleation ability of the ice-cloud processed aerosol particles in the respective second expansion runs of Exps. 4 and 5 is discussed in the following. 

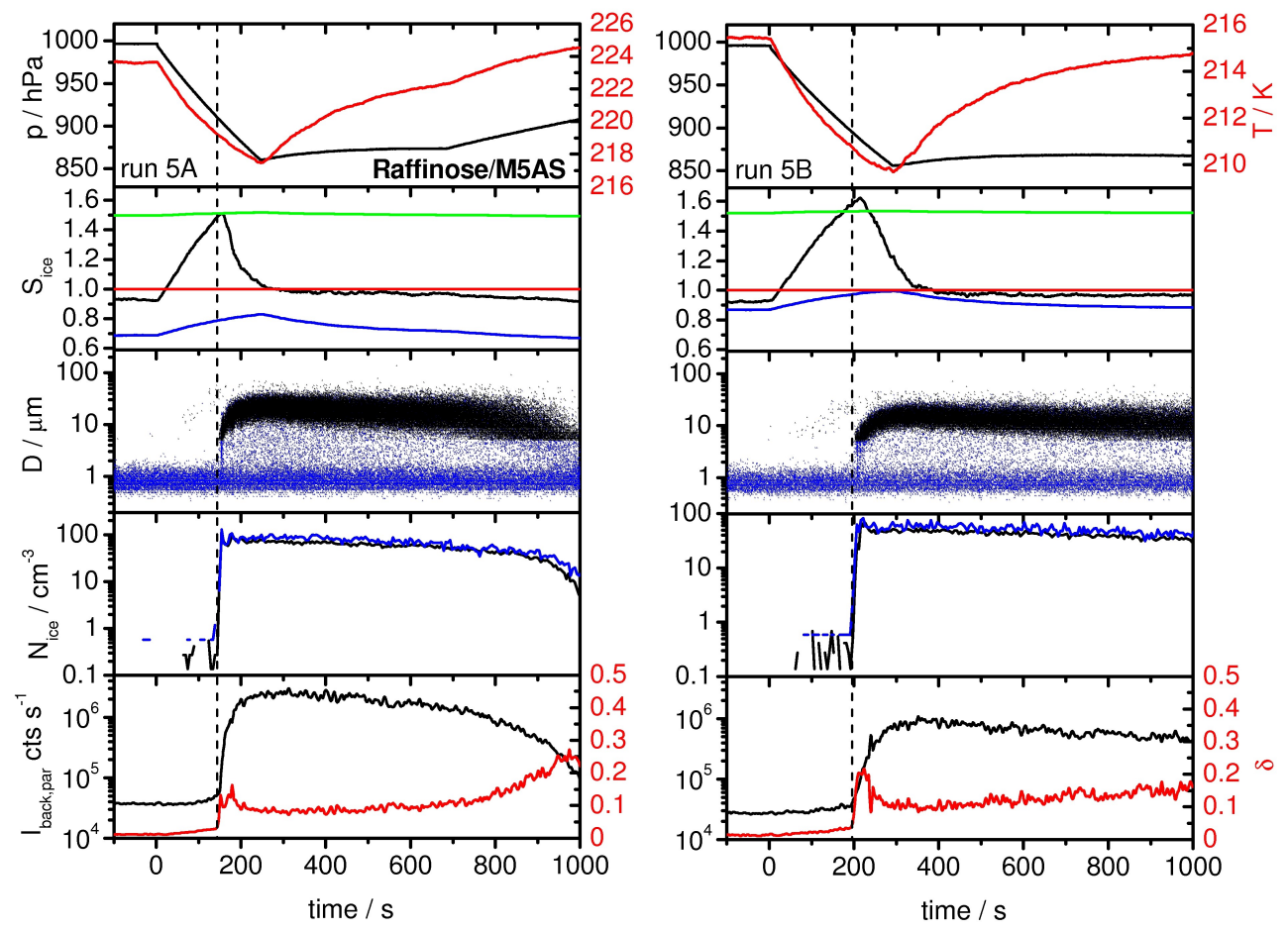

Fig. 13. Time series of various AIDA records during expansion runs 5A and 5B with raffinose/M5AS aerosol particles. The individual panels contain the same measurements as in Fig. 5.

Figure 12 shows the AIDA records from the pair of repetitive expansion runs conducted with raffinose/M5AS aerosol particles which were both started at a temperature close to $T_{\mathrm{g}}^{\prime}$ (Exp. 4). They feature the previously observed pre-activation behaviour, albeit revealing notable differences compared to the experiments with HMMA and raffinose. The experimental procedure prior to these expansion cycles was as follows. The aerosol particles were injected in the liquid regime at $236 \mathrm{~K}$ and the chamber was then directly cooled to $193 \mathrm{~K}$ without performing any intermediate expansion runs. In the first expansion cycle that was conducted at $193 \mathrm{~K}$, and, similarly, in the second expansion cycle that was performed later on after warming the chamber to $202 \mathrm{~K}$, heterogeneous ice nucleation on the glassy aqueous raffinose/M5AS particles could be detected (Table A1). The AIDA vessel was then warmed to $216 \mathrm{~K}$ to perform a series of three repetitive expansion runs. The data from the first two of these three cycles are depicted in Fig. 12. We call these expansion cycles run $4 \mathrm{~A}$ and run $4 \mathrm{~B}$, i.e., do not consider in the labelling the previous expansion runs conducted deeply in the glassy regime which did not alter the ice nucleation ability of the aerosol load.

Run 4A shows a dominant homogeneous freezing mode with $N_{\text {ice }}=100 \mathrm{~cm}^{-3}$. The nucleation threshold (vertical dashed line) closely agrees with the parameterisation by Koop et al. (2000). Only a very small number concentration of ice crystals $\left(N_{\text {ice }}\right.$ less than $0.5 \mathrm{~cm}^{-3}$ ) was heterogeneously formed prior to the homogeneous freezing onset, which is not significantly above the ice particles nucleated on background aerosol impurities. According to the parameterisation of the glass transition for raffinose/M5AS by Zobrist et al. (2008), run 4A was started in the highly viscous regime slightly above the glass transition relative humidity (second panel in Fig. 12). Nonetheless, we observed an enhanced ice nucleation ability of the ice cloud processed raffinose/M5AS particles in the succeeding expansion run $4 \mathrm{~B}$. This might suggest that the pre-activation behaviour is not strictly limited to the glassy state but also occurs in the highly viscous regime. However, as already addressed in the context of Fig. 1, the glass transition parameterisation on the water activity scale by Zobrist et al. (2008) is affected by a higher uncertainty at lower temperatures because the water activities of the various solutes were only measured at higher temperatures and needed to be extrapolated to lower temperatures. The aerosol particles probed in run 4A might therefore still have been in the glassy state.

During the pre-activation run $4 \mathrm{~B}$, an early ice particle mode is formed at a threshold of $S_{\text {ice }}=1.3$ (first vertical line, Fig. 12). This critical ice saturation ratio is much higher than in the pre-activation runs with the HMMA and raffinose aerosol particles, and, interestingly, nucleation occurs although $S_{\text {ice }}$ has already clearly exceeded the glass transition relative humidity. The number concentration of nucleated ice crystals in the pre-activation mode amounts to about 


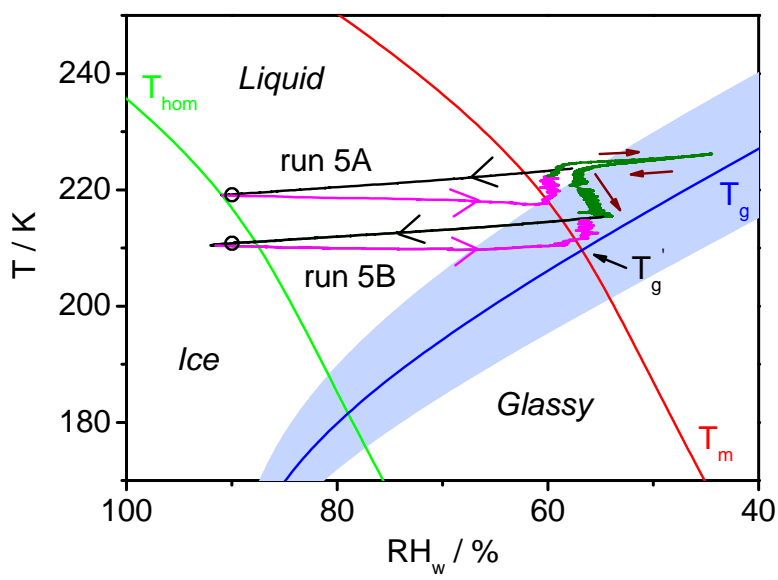

Fig. 14. Experimental trajectories of expansion runs $5 \mathrm{~A}$ and $5 \mathrm{~B}$ as a function of $\mathrm{RH}_{\mathrm{w}} . T_{\mathrm{g}}$ denotes the glass transition temperature, $T_{\mathrm{m}}$ the ice melting temperature, and $T_{\text {hom }}$ the homogeneous freezing temperature. The same colour code as in the bottom panel of Fig. 7 is used to underline the temporal order of the experiment. The circles denote the onsets of ice nucleation during the expansion runs, whose further AIDA records are shown in Fig. 13. The fit parameters of the water activity measurements for raffinose/M5AS solutions of different concentrations, not included in Table A4 of Zobrist et al. (2008), were obtained from the authors upon request. They are: $\mathrm{a}=-1, \mathrm{~b}=-0.93366, \mathrm{c}=0.14602, \mathrm{~d}=0.0027723$, $\mathrm{e}=-0.0049331, \mathrm{f}=-0.0037756$, and $\mathrm{g}=0.0059027$. Together with the parameterisation of $T_{\mathrm{g}}$ as function of the raffinose/M5AS weight fraction, the curve of the glass transition temperature (blue line) and its uncertainty estimate (blue shaded area) were computed. Note that for Exp. 4, both the trajectories of run 4A and run 4B approximately fall into the regime of that of run $5 \mathrm{~B}$.

$3 \mathrm{~cm}^{-3}$ and is much smaller than in the HMMA and raffinose pre-activation runs. During continued pumping in run $4 \mathrm{~B}$, the ice saturation ratio easily exceeds the homogeneous freezing threshold and a second ice crystal mode with $N_{\text {ice }}=60 \mathrm{~cm}^{-3}$ is formed (second vertical line). A similar dual nucleation event was detected in the third repetitive expansion cycle conducted at $216 \mathrm{~K}$ whose data are not shown. Potential explanations for the poorer ice nucleation ability of the raffinose/M5AS aerosol particles in the pre-activation run, as expressed by a higher nucleation threshold and a lower ice crystal number concentration, are discussed in the next section. In the following, we want to briefly describe the other experiment with the raffinose/M5AS mixture (Exp. 5) which underlines that the pre-activation mode from run $4 \mathrm{~B}$, although being less pronounced, can only be triggered by a preceding homogeneous freezing run in the highly viscous or glassy regime.

In Fig. 13, the AIDA data are shown for the couple of repetitive expansion runs from Exp. 5 where the second run $5 \mathrm{~B}$ was started at the same temperature as run 4B $(216 \mathrm{~K})$. The preceding homogeneous freezing run $5 \mathrm{~A}$, however, was started in the liquid regime at $224 \mathrm{~K}$ where the initial ice sat- uration ratio (black line, second panel) was clearly above the glass transition relative humidity (blue line). To underline the different starting points of runs $5 \mathrm{~A}$ and $5 \mathrm{~B}$, we have additionally plotted their experimental trajectories as a function of $\mathrm{RH}_{\mathrm{w}}$ (Fig. 14), similar to the lower panel of Fig. 7 (Sect. 4.2). As apparent from Fig. 13, the ice nucleation behaviour does not change between the two repetitive expansion cycles. Also in run 5B, only homogeneous freezing occurs and the early pre-activation ice mode observed during run $4 \mathrm{~B}$ is absent. The homogeneous freezing run conducted in the liquid regime therefore does not promote enhanced ice nucleation ability in the succeeding expansion cycle. A pair of repetitive expansion runs in the liquid regime above $T_{\mathrm{g}}^{\prime}$ was also conducted with levoglucosan aerosol particles and yielded the same result, i.e., both succeeding expansion cycles only showed homogeneous freezing.

\subsection{Discussion}

\subsubsection{Overview of the experimental results}

We start our discussion with a summary of the major findings from the previous four sections.

- Glassy aqueous aerosol particles reveal an enhanced ice nucleation ability after having been processed in a homogeneous freezing cycle that was conducted in the regime below $T_{\mathrm{g}}^{\prime}$ and above the upper threshold temperature where heterogeneous ice nucleation in the deposition mode on the vitrified particles could be observed.

- A homogeneous freezing run that was conducted well above $T_{\mathrm{g}}^{\prime}$, i.e. with unambiguously liquid aerosol, does not alter the ice nucleation ability.

- The pre-activation behaviour disappears when the chamber temperature is increased above $T_{\mathrm{g}}^{\prime}$ after the pre-activation run. In contrast, the pre-activation behaviour is conserved even if the aerosol is maintained for hours at ice-subsaturated conditions in the glassy regime with a minimum $S_{\text {ice }}$ value of 0.7 .

- The pre-activation behaviour is completely conserved in repeated pre-activation runs as long as the ice saturation ratio does not exceed the glass transition relative humidity during the pre-activation cycle. If the latter happens, the number concentration of pre-activated seed aerosol particles which trigger early ice formation seems to decrease but the pre-activation mode does not completely disappear.

- The onset of ice nucleation in the first pre-activation runs with HMMA and raffinose occurs at a supersaturation of $5-12 \%$ with respect to ice. Only for the preactivation runs conducted with raffinose/M5AS, a significantly higher threshold of about $30 \%$ was observed. 


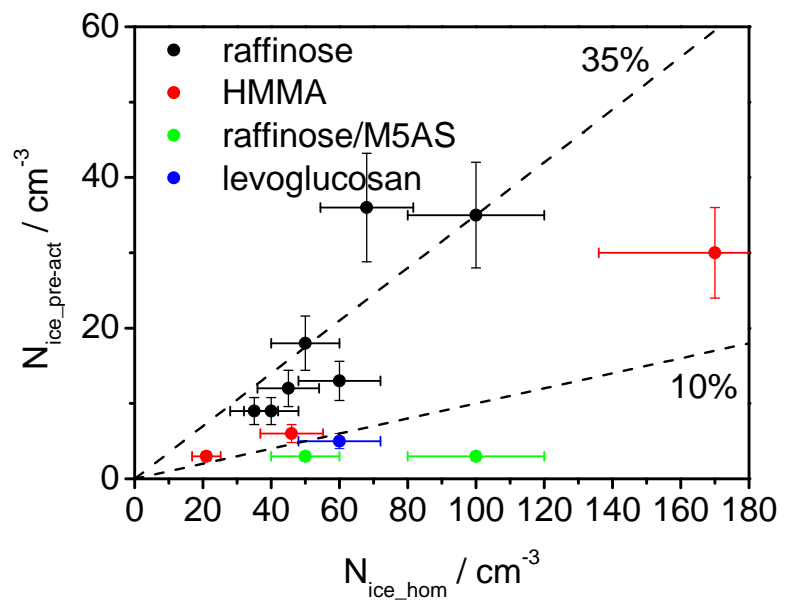

Fig. 15. Correlation of the ice particle number concentrations

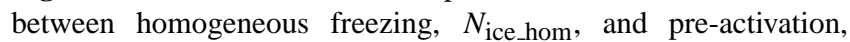
$N_{\text {ice_pre-act }}$, for all couples of succeeding expansion runs that were conducted in the present study with the four different compounds. The two dashed lines denote 10 and $35 \%$ fractions of $N_{\text {ice_hom }}$.

- The number concentration of ice crystals formed in the pre-activation run is always a subset of that from the preceding homogeneous freezing cycle. As a quantitative illustration, Fig. 15 shows the correlation of the ice crystal number concentrations between homogeneous freezing and pre-activation for all pairs of subsequent expansion runs that were conducted in the present study. Typically, a $10-35 \%$ fraction of the ice particle number concentration from the homogeneous freezing run is observed in the subsequent pre-activation run. Only for the experiments with the raffinose/M5AS mixture, this fraction is much smaller.

We consider two possible explanations to account for the enhanced ice nucleation ability of the ice cloud processed aerosol particles: (i) ice surface mediated crystallisation of the solute during homogeneous freezing which may then catalyse ice formation, and (ii) the production of preactivated glassy aerosol. In the following we present evidence that suggests solute crystallisation is very unlikely and that the most likely explanation for the observed enhanced ice nucleation ability is the production of pre-activated glassy aerosol particles.

\subsubsection{Evidence against ice catalysed solute crystallisation}

Soluble crystalline materials such as ammonium sulphate, sodium chloride, or oxalic acid are known to heterogeneously catalyse ice formation (Abbatt et al., 2006; Kanji et al., 2008; Wagner et al., 2010; Wise et al., 2012; Zobrist et al., 2006). If the solutes used in our present study were to crystallise during homogeneous freezing they might nucleate ice heterogeneously in the succeeding expansion cycle.

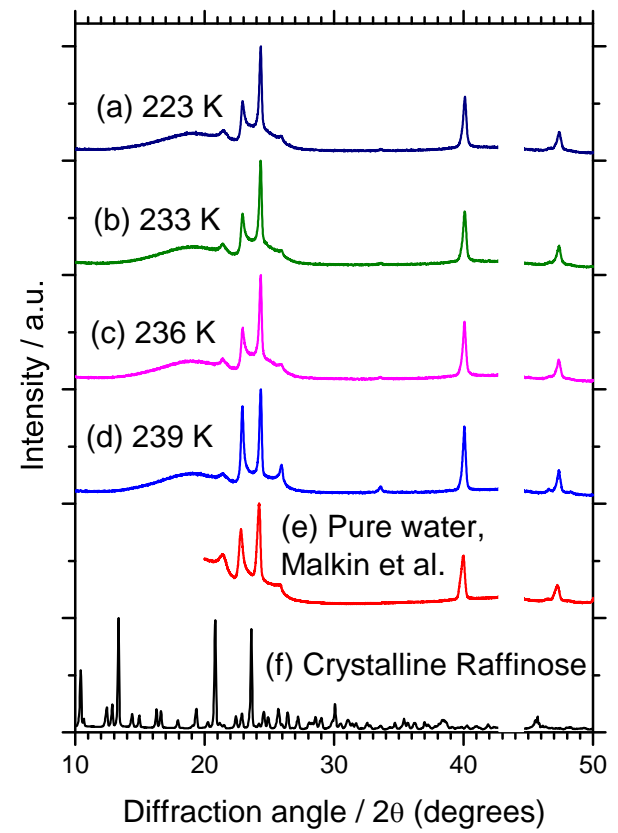

Fig. 16. X-ray diffraction patterns of frozen aqueous raffinose droplets. These $15 \mathrm{wt} \%$ raffinose in water droplets were on the order of $10 \mu \mathrm{m}$ and suspended in an oil emulsion. The emulsion was cooled at a rate of $30 \mathrm{~K} \mathrm{~min}^{-1}$ to $223 \mathrm{~K}$ where diffraction pattern (a) was recorded. Diffraction patterns (b) to (d) were recorded after warming the emulsion to successively greater temperatures as indicated in the plot. The diffraction pattern of ice which resulted from the freezing of pure water droplets (resulting in the newly identified stacking disordered ice, ice $\mathrm{I}_{\mathrm{sd}}$ ) is also shown as (e) (Malkin et al., 2012). The diffraction pattern of a powder sample of crystalline raffinose measured on the same instrument is included as (f).

However, as soon as ice nucleates within a temporarily liquefied organic solution droplet during an expansion run of type 2 shown in Fig. 1, the composition of the unfrozen aqueous medium will adjust towards that defined by ice saturation. Since ice saturation is below the glass transition relative humidity, the freeze concentrated solute may therefore become ultra-viscous or vitrify before it has a chance to crystallise. This was clearly the case in citric acid solutions where solute crystallisation was not observed at any freezing temperature and is consistent with the fact that nucleation rates are greatly reduced in viscous liquids (Murray, 2008a). In order to test for crystallisation under conditions used in the present study we performed an experiment using X-ray diffraction to probe crystallisation in aqueous raffinose droplets.

Droplets of $15 \mathrm{wt} \%$ raffinose in water were suspended in an oil emulsion and mounted on the cold stage of an X-ray diffractometer according to the procedure detailed by Malkin et al. (2012). These droplets, which were on the order of $10 \mu \mathrm{m}$ in diameter, were cooled at $30 \mathrm{~K} \mathrm{~min}^{-1}$ to $223 \mathrm{~K}$. The droplets froze at $236 \pm 1.0 \mathrm{~K}$ and once at $223 \mathrm{~K}$ a diffraction pattern was recorded and this is shown in Fig. 16 (pattern a). The diffraction pattern is very similar to that for 
frozen pure water droplets (pattern e) reported by Malkin et al. (2012). Malkin et al. (2012) show that this metastable ice which was formerly named cubic ice is in fact stacking disordered ice (ice $\mathrm{I}_{\mathrm{sd}}$ ) and lacks cubic or hexagonal symmetry. Peaks from crystalline raffinose (f) are absent. On warming the droplets to $239 \mathrm{~K}$ crystallisation was still not observed (patterns b-d). These experiments indicate that raffinose did not crystallise in more than $2 \%$ of the droplets (based on sensitivity tests with crystalline raffinose suspended in the oil emulsion). In addition, ice catalysed solute crystallisation should be less likely in smaller droplets (Murray and Bertram, 2008) and the X-ray diffraction experiments were done with droplets at least one order of magnitude larger than those in the AIDA chamber. These experiments confirm that raffinose did not crystallise when raffinose solution droplets froze in the chamber experiments and it seems unlikely that crystallisation occurs in any of the other systems studied here given they all readily form viscous or glassy freeze concentrated solutions (Zobrist et al., 2008).

In agreement with the X-ray experiments, we have never detected an increase in the depolarisation ratio after the ice crystals from the homogeneous freezing runs had sublimed which would indicate crystallisation of the seed aerosol particles. However, only a small number fraction of the overall aerosol load homogeneously nucleates ice during the expansion run and thus has a chance to crystallise. This technique might therefore not be sensitive enough to clearly evidence the absence of crystallisation. Furthermore, the magnitude of the depolarisation level might also be low for particular habits of the crystallised particles (Zakharova and Mishchenko, 2000). A series of other more substantial arguments also support our conclusion that the solute crystallisation mechanism almost certainly does not account for the experimental observations.

1. Pre-activation was absent in expansion run 5B (Fig. 13) whereas it was observed during run $4 \mathrm{~B}$ (Fig. 12). Both of these runs were done at similar temperatures $(\sim 216 \mathrm{~K})$, but the preceding runs were started at different temperatures. For run $4 \mathrm{~B}$, the preceding homogeneous freezing run was at $\sim 216 \mathrm{~K}$, i.e. close to $T_{\mathrm{g}}^{\prime}$, and a clear pre-activation signal was observed, but in $5 \mathrm{~B}$ the preceding homogeneous run was at $\sim 224 \mathrm{~K}$ and no significant pre-activation was observed. This provides a strong argument against ice mediated solute crystallisation being significant since crystallisation would be expected to occur at both 216 and $224 \mathrm{~K}$ and this clearly did not happen otherwise pre-activation would have been observed in both $5 \mathrm{~B}$ and $4 \mathrm{~B}$.

2. Assuming that the temperature increase of $15 \mathrm{~K}$ between run 1D and run 1E with HMMA (Fig. 4) would not significantly alter the ice nucleation ability of potentially crystallised HMMA particles, the absence of heterogeneous ice nucleation in run $1 \mathrm{E}$ cannot be adequately explained by the crystallisation mechanism be- cause the crystals having promoted heterogeneous ice nucleation in run 1D should still have been present in the succeeding expansion run.

3. In a recent study, we have shown for ternary solution droplets composed of sulphuric acid, oxalic acid, and water that the efficiency of the ice surface mediated crystallisation of oxalic acid was very low under the conditions of a typical AIDA expansion cooling run (Wagner et al., 2011). Less than $1 \%$ of the ice crystals generated in a preceding homogeneous freezing run left behind an ice-active oxalic acid crystal that promoted heterogeneous ice nucleation in a succeeding expansion cycle. In the present experiments with the ultraviscous/glassy aerosol particles, the observed fraction of frozen droplets which become pre-activated is much higher and typically between 10 and $35 \%$ (Fig. 15).

\subsubsection{An alternative explanation: pre-activation of the glassy aerosol particles}

Rather than ice catalysed solute crystallisation, we propose a different mechanism to explain the modified ice nucleation ability of the glassy aqueous aerosol particles. As indicated in the introduction, we chose the term pre-activation for this behaviour due to similarities with the well-known phenomenon of pre-activation of insoluble ice nuclei in heterogeneous ice nucleation (Mossop, 1956; Pruppacher and Klett, 1997; Roberts and Hallett, 1968; Vali, 2008). After ice crystals have formed on solid seed aerosol particles like mineral dust in a first nucleation event, small embryos of ice might survive even at relative humidities well below $S_{\text {ice }}=1$ in suitable cavities or crevices at the particle surface. These embryos would then reduce the threshold ice saturation ratio for heterogeneous nucleation in a succeeding experiment. Note that such ice embryos in capillaries of solid particles might also be formed in a subsaturated environment without a preceding ice nucleation event by a two-step process involving freezing of condensed supercooled water (Higuchi and Fukuta, 1966; Kovács et al., 2012). Alternatively, it was proposed that the ice crystals from the first nucleation event could imprint their structure on the surface of soft materials (Vali, 2008; Zuberi et al., 2001). This would lead to a surface structure that more closely resembles the ice lattice and that could then promote heterogeneous ice nucleation as an activated site at a lower threshold relative humidity.

We propose that a similar mechanism also holds for the pre-activation of the glassy aerosol particles. One might easily imagine that the freeze concentrated solution which vitrifies in contact with ice after homogeneous freezing retains a footprint of the ice layer on its own surface, explaining the reduced nucleation threshold in the pre-activation run. Furthermore, the surface microstructure of the ice-cloud processed glassy aerosol particles will most likely not be as smooth as that formed in an unperturbed environment by slowly cooling the ensemble of injected liquid aqueous solution droplets 
below the glass transition temperature before probing them in the initial homogeneous freezing cycle. The process of ice growth in the liquefied aqueous droplets, re-vitrification of the freeze-concentrated solution, and subsequent sublimation of ice may leave behind a porous glassy core with potential surface defects and with a larger surface area compared to a smooth sphere. On the one hand, small domains or pores filled with ice might persist at or close to the surface of the re-vitrified amorphous glassy particles which become activated at low supersaturation levels in the succeeding expansion run. On the other, even if ice embryos would not survive below $S_{\text {ice }}=1$, the larger surface area or modified surface microstructure of the ice-cloud processed glassy aerosol particles might promote ice nucleation at much lower supersaturations. Similar arguments were given by Zuberi et al. (2001) to account for the morphology dependent ice nucleation ability of crystalline ammonium sulphate particles.

These interpretations account for most of the observations as summarised at the beginning of the section, in particular for the absence of pre-activation in repeated expansion runs in the liquid regime. Also, ice embryos, ice footprints or a high surface area glass will be lost if the chamber temperature is raised above $T_{\mathrm{g}}^{\prime}$ and the aerosol load becomes liquid, again consistent with our data. As long as the relative humidity remains below the glass transition relative humidity in a pre-activation run (Sect. 4.3, Exp. 3), the surface structure of the pre-activated particles is preserved. Thereby, the ice nucleation behaviour remains unchanged in a succeeding expansion cycle. It is not straightforward to predict the effect on the pre-activation behaviour if the relative humidity is temporarily raised above the glass transition relative humidity during the pre-activation run. There is at least the chance that the pre-activated glassy aerosol particles undergo another glass-to-liquid and re-vitrification cycle leading to a smoothening of their surface structure, at the outcome of which a fraction of the pre-activated particles may get deprived of their enhanced ice nucleation ability. The experimental findings (runs $3 \mathrm{~F}-3 \mathrm{H}$ ) seem to corroborate this assumption but they are not unambiguous because a fraction of the pre-activated particles will necessarily be lost in repeated expansion runs due to continued pumping and sedimentation. The successive homogeneous freezing and preactivation runs with the raffinose/M5AS seed aerosols (runs $4 \mathrm{~A}$ and $4 \mathrm{~B}$ ) were most probably performed in the transition regime between amorphous solid and ultra-viscous liquid particles. One might therefore explain the reduced preactivation behaviour of the raffinose/M5AS particles by arguing that footprints or embryos of ice are less efficiently conserved in ultra-viscous aerosols featuring a higher molecular mobility of water compared to the glassy state that was prevalent in the experiments with raffinose and HMMA.

\subsubsection{Atmospheric implications}

Pre-activation represents another pathway by which glassy aerosol particles can promote ice nucleation below the homogeneous freezing limit in addition to heterogeneous nucleation in the deposition mode which occurs when glassy aerosols are well below $T_{\mathrm{g}}^{\prime}$ without preceding expansion run (Murray et al., 2010; Wilson et al., 2012). The nucleation threshold after pre-activation is typically much lower than observed for deposition nucleation of ice on the glassy particles.

The atmospheric significance of the pre-activation mechanism remains to be discussed. One important issue concerning the efficiency of the pre-activation behaviour arises when transferring the AIDA findings to atmospheric conditions. We have shown that the enhanced ice nucleation behaviour is preserved for several hours even if the ice cloud processed glassy aerosol particles are exposed to an icesubsaturated environment with $S_{\text {ice }}$ in the range from $0.7-$ 0.8 (Exp. 2, Sect. 4.2). The nucleation threshold in the preactivation run $2 \mathrm{C}$, however, was slightly higher than in typical pre-activation runs conducted only $30 \mathrm{~min}$ after the homogeneous freezing run (e.g. run 3C). On the one hand, this might be simply due to the different starting temperatures between run $2 \mathrm{C}(224 \mathrm{~K})$ and run $3 \mathrm{C}(230 \mathrm{~K})$. On the other, potential ice embryos in pores might sublime when the particles are exposed to $S_{\text {ice }}<1$ for long time periods or the surface properties of the porous glassy aerosol particles might change, thereby explaining the different nucleation thresholds between run $2 \mathrm{C}$ and run 3C. Further experiments are needed to confirm whether this was just a singular observation or a general trend which might even get more dominant for longer time periods of one or several days before the second freezing cycle and/or exposure to ambient relative humidities lower than $70 \%$ with respect to ice.

Addressing the atmospheric scenario, first homogeneous freezing would be required in order to generate pre-activated aerosol particles. Only those aerosol particles which are a few degrees below their $T_{\mathrm{g}}^{\prime}$ will become pre-activated. In contrast to laboratory experiments with uniform aerosol particles with a specific $T_{\mathrm{g}}^{\prime}$, in the real atmosphere there is likely a distribution of aerosol composition featuring a range of $T_{\mathrm{g}}^{\prime}$ values. A subset of this population will therefore always be in the right regime when homogeneous freezing occurs at a given temperature. If these pre-activated aerosol particles are to serve as ice nuclei in subsequent cloud formation cycles then they must at no point warm sufficiently to undergo amorphous deliquescence. One might envisage a scenario in which a cloud forms in situ in the upper troposphere via homogeneous nucleation, followed by growth and sedimentation of ice particles and release of pre-activated aerosol at a lower altitude. As discussed above, only a fraction of the aerosol which activated homogeneously to ice might become pre-activated, since not all aerosol particles in a natural aerosol will have the pertinent $T_{\mathrm{g}}^{\prime}$. These aerosol particles 
may then catalyse ice formation in a subsequent cloud formation event at a much lower supersaturation and this will result in a cloud with far fewer cloud ice crystals. The importance of this potential mechanism needs to be assessed by quantitative cloud models in which pre-activated aerosol are tracked until they enter a new cloud and nucleated ice or become deactivated.

\section{Summary}

We have presented cloud chamber measurements on the ice nucleation ability of airborne glassy aqueous aerosol particles unravelling a new mechanism by which these aerosol particles can promote ice nucleation at very low supersaturation levels. From a previous study it was known that glassy aerosols can heterogeneously catalyse ice formation before the onset of homogeneous freezing in expansion experiments conducted at temperatures well below $T_{\mathrm{g}}^{\prime}$. In freezing cycles started only slightly below $T_{\mathrm{g}}^{\prime}$, the glass-to-liquid transition occurs before the heterogeneous freezing mode becomes active. Ice formation then only takes place at elevated relative humidities due to homogeneous freezing. During ice growth within the aqueous droplets the solute freeze concentrates and re-vitrifies. Then on sublimation of the ice a glassy core remains which may be porous. If these ice cloud processed glassy aerosol particles are then probed in a second expansion cycle at the same temperature, they have an enhanced ice nucleation ability, as evident by ice formation at a supersaturation level between 5 and $30 \%$ with respect to ice.

We have termed this modified ice nucleation ability in repeated expansion runs in the glassy regime as pre-activation behaviour, arguing that it is analogous to pre-activation of insoluble ice nuclei in heterogeneous ice nucleation. A number of mechanisms have been proposed to explain the enhanced ice nucleation ability: the retention of ice embryos within pores, footprints of ice on the glass which match the ice lattice or simply an enhanced surface area of the porous glassy particles. We have shown that ice-surface catalysed crystallisation of the freeze-concentrated organic solutions with subsequent heterogeneous ice nucleation in the deposition mode on the organic crystals most likely does not account for our observations. This was ruled out on the basis of X-ray diffraction work in which the solute was shown not to crystallise on freezing raffinose droplets and it is also inconsistent with a number of our expansion experiments: preactivation is not observed in repeated expansion cycles above $T_{\mathrm{g}}^{\prime}$ and also disappears when the pre-activated aerosol population passes from the glassy to the liquid regime of the state diagram. Hence, we conclude that the pre-activation is clearly linked to the glass transition temperature, $T_{\mathrm{g}}^{\prime}$.

The pre-activation behaviour was detected in experiments with four different solutes having glass transition temperatures between 210 and $240 \mathrm{~K}$ which were used as surrogates for oxidised organic matter found in the atmosphere. For assessing its atmospheric impact, it must, however, be considered that an air parcel with glass-forming organic aerosol particles has to follow a particular trajectory to become pre-activated. At first, a homogeneous freezing cycle below the glass transition temperature of the prevalent multicomponent mixture of organic and inorganic solutes is required. After the sublimation of the nucleated ice crystals, the air parcel must remain in the glassy regime of the state diagram before passing the second freezing cycle where the enhanced ice nucleation ability then becomes evident. Detailed calculations with a cloud model, being beyond the scope of the present experimental work, are needed to estimate the fraction of trajectories in the upper troposphere which fulfil these requirements for air parcels containing particles with different glass transition temperatures. In addition, further laboratory studies where the time spent below ice saturation and the surrounding relative humidity between the initial homogeneous freezing and the succeeding pre-activation run are systematically varied are highly desirable in order to investigate whether these parameters influence the efficiency of the pre-activation behaviour in terms of the freezing threshold and the number concentration of nucleated ice crystals.

\section{Appendix A}

\section{Supplementary information from the companion paper by Wilson et al. (2012)}

The experiments described in this manuscript probe the ice nucleation ability of various glassy aerosol particles in the temperature range between $T_{\mathrm{g}}^{\prime}$ and the upper threshold temperature, $T_{\max }^{\text {het }}$, where heterogeneous ice nucleation in the deposition mode is observed at a given critical ice saturation ratio, $S_{\text {ice }}^{\text {het }}$. The latter mechanism is analysed in the companion paper by Wilson et al. (2012). As a look-up table for the reader, we have compiled the $T_{\mathrm{g}}^{\prime}, T_{\max }^{\text {het }}$, and $S_{\text {ice }}^{\text {het }}$ values for all investigated compounds (Table A1). The $T_{\max }^{\text {het }}$ and $S_{\text {ice }}^{\text {het }}$ values correspond to the blue stars on the trajectories of the expansion runs shown in Fig. 7 of Wilson et al. (2012), representing the heterogeneous ice nucleation onsets. The final column of Table A1 briefly describes the chemical functionality and atmospheric significance of the employed compounds. 
Appendix A1. Supplementary information on the heterogeneous ice nucleation ability, chemical functionality, and atmospheric significance of the investigated compounds from the companion paper by Wilson et al. (2012). See text for details.

\begin{tabular}{|c|c|c|c|c|}
\hline Solute & $T_{\mathrm{g}}^{\prime} / \mathrm{K}$ & $T_{\max }^{\text {het }} / \mathrm{K}$ & $S_{\text {ice }}^{\text {het }}$ & Functionality and atmospheric significance \\
\hline HMMA & 236.5 & 218 & 1.20 & $\begin{array}{l}\text { Aromatic compound, surrogate for water soluble } \\
\text { organic compounds in atmospheric aerosol }\end{array}$ \\
\hline Levoglucosan & 211.7 & 191 & 1.55 & $\begin{array}{l}\text { Monosaccharide anhydride, major component } \\
\text { of biomass burning aerosol }\end{array}$ \\
\hline Raffinose & 240.6 & 215 & 1.33 & Trisaccharide, component of biomass burning aerosol \\
\hline Raffinose/M5AS & 209.6 & 200 & 1.21 & $\begin{array}{l}\text { Multi-component oxidised organic/sulphate mixture, } \\
\text { representing internally mixed atmospheric aerosol }\end{array}$ \\
\hline
\end{tabular}

Acknowledgements. The authors are grateful to all members of the AIDA staff for their continuous support during the numerous successful measurement campaigns on ice nucleation which have been conducted at the chamber facility in the past decade. The work has been funded by the Helmholtz-Gemeinschaft deutscher Forschungszentren as part of the program "Atmosphere and Climate" and by the EUROCHAMP-2 (Integration of European Simulation Chambers for Investigating Atmospheric Processes) project within the EC 7th framework programme. BJM and TWW acknowledge the European Research Council for funding (240449 - ICE). We acknowledge support by Deutsche Forschungsgemeinschaft and Open Access Publishing Fund of Karlsruhe Institute of Technology.

The service charges for this open access publication

have been covered by a Research Centre of the

Helmholtz Association.

Edited by: T. Koop

\section{References}

Abbatt, J. P. D., Benz, S., Cziczo, D. J., Kanji, Z., Lohmann, U., and Möhler, O.: Solid ammonium sulfate aerosols as ice nuclei: A pathway for cirrus cloud formation, Science, 313, 1770-1773, 2006.

Bodsworth, A., Zobrist, B., and Bertram, A. K.: Inhibition of efflorescence in mixed organic-inorganic particles at temperatures less than 250 K, Phys. Chem. Chem. Phys., 12, 12259-12266, 2010.

Debenedetti, P. G. and Stillinger, F. H.: Supercooled liquids and the glass transition, Nature, 410, 259-267, 2001.

Higuchi, K. and Fukuta, N.: Ice in Capillaries of Solid Particles and Its Effect on Their Nucleating Ability, J. Atmos. Sci., 23, 187190, 1966.

Hinds, W. C., Aerosol Technology, John Wiley \& Sons, Inc., New York, USA, 51-55, 1999.

Kanji, Z. A., Florea, O., and Abbatt, J. P. D.: Ice formation via deposition nucleation on mineral dust and organics: dependence of onset relative humidity on total particulate surface area, Environ. Res. Lett., 3, 025004, doi:10.1088/1748-9326/3/2/025004, 2008.

Koop, T., Luo, B. P., Tsias, A., and Peter, T.: Water activity as the determinant for homogeneous ice nucleation in aqueous solutions, Nature, 406, 611-614, 2000.
Koop, T., Bookhold, J., Shiraiwa, M., and Pöschl, U.: Glass transition and phase state of organic compounds: dependency on molecular properties and implications for secondary organic aerosols in the atmosphere, Phys. Chem. Chem. Phys., 13, 19238-19255, 2011.

Kovács, T., Meldrum, F. C., and Christenson, H. K.: Crystal Nucleation without Supersaturation, J. Phys. Chem. Lett., 3, 1602 1606, 2012.

Li, K. K., Wang, F., Zeng, G., Reid, J. P., and Zhang, Y. H.: Probing the Time Scale for Bulk Equilibration and Mass Transport of Water in Amorphous Inorganic Aerosol, J. Phys. Chem. B, 115, 14397-14403, 2011.

Malkin, T. M., Murray, B. J., Brukhno, A. V., Anwar, J., and Salzmann, C. G.: Structure of ice crystallized from supercooled water, Proc. Natl. Acad. Sci. USA, 4, 1041-1045, 2012.

Mikhailov, E., Vlasenko, S., Martin, S. T., Koop, T., and Pöschl, U.: Amorphous and crystalline aerosol particles interacting with water vapor: conceptual framework and experimental evidence for restructuring, phase transitions and kinetic limitations, Atmos. Chem. Phys., 9, 9491-9522, doi:10.5194/acp-9-9491-2009, 2009.

Mishchenko, M. I., Travis, L. D., and Mackowski, D. W.: T-matrix computations of light scattering by nonspherical particles: A review, J. Quant. Spectrosc. Radiat. Trans., 55, 535-575, 1996.

Möhler, O., Stetzer, O., Schaefers, S., Linke, C., Schnaiter, M., Tiede, R., Saathoff, H., Krämer, M., Mangold, A., Budz, P., Zink, P., Schreiner, J., Mauersberger, K., Haag, W., Kärcher, B., and Schurath, U.: Experimental investigation of homogeneous freezing of sulphuric acid particles in the aerosol chamber AIDA, Atmos. Chem. Phys., 3, 211-223, doi:10.5194/acp-3-211-2003, 2003.

Möhler, O., Field, P. R., Connolly, P., Benz, S., Saathoff, H., Schnaiter, M., Wagner, R., Cotton, R., Krämer, M., Mangold, A., and Heymsfield, A. J.: Efficiency of the deposition mode ice nucleation on mineral dust particles, Atmos. Chem. Phys., 6, 30073021, doi:10.5194/acp-6-3007-2006, 2006.

Mossop, S. C.: Sublimation Nuclei, P. Phys. Soc. Lond. B, 69, 161164, 1956.

Murphy, D. M. and Koop, T.: Review of the vapour pressures of ice and supercooled water for atmospheric applications, Q. J. Roy. Meteorol. Soc., 131, 1539-1565, 2005.

Murray, B. J.: Enhanced formation of cubic ice in aqueous organic acid droplets, Environ. Res. Letters, 3, 025008, doi:10.1088/1748-9326/3/2/025008, 2008a. 
Murray, B. J.: Inhibition of ice crystallisation in highly viscous aqueous organic acid droplets, Atmos. Chem. Phys., 8, 54235433, doi:10.5194/acp-8-5423-2008, 2008b.

Murray, B. J. and Bertram, A. K., Inhibition of solute crystallisation in aqueous $\mathrm{H}^{+}-\mathrm{NH}_{4}^{+}-\mathrm{SO}_{4}^{2-}-\mathrm{H}_{2} \mathrm{O}$ droplets, Phys. Chem. Chem. Phys., 10, 3287-3301, 2008.

Murray, B. J., Wilson, T. W., Dobbie, S., Cui, Z., Al-Jumur, S. M. R. K., Möhler, O., Schnaiter, M., Wagner, R., Benz, S., Niemand, M., Saathoff, H., Ebert, V., Wagner, S., and Kärcher, B.: Heterogeneous nucleation of ice particles on glassy aerosols under cirrus conditions, Nature Geosci., 3, 233-237, 2010.

Murray, B. J., Haddrell, A. E., Peppe, S., Davies, J. F., Reid, J. P., O'Sullivan, D., Price, H. C., Kumar, R., Saunders, R. W., Plane, J. M. C., Umo, N. S., and Wilson, T. W.: Glass formation and unusual hygroscopic growth of iodic acid solution droplets with relevance for iodine mediated particle formation in the marine boundary layer, Atmos. Chem. Phys., 12, 8575-8587, doi:10.5194/acp-12-8575-2012, 2012.

Pruppacher, H. R. and Klett, J. D.: Microphysics of Clouds and Precipitation, Kluwer Acacdemic Publishers, Dordrecht, The Netherlands, 319-320, 337-338, 1997.

Roberts, P. and Hallett, J.: A Laboratory Study of Ice Nucleating Properties of Some Mineral Particulates, Q. J. Roy. Meteorol. Soc., 94, 25-34, 1968.

Schnaiter, M., Büttner, S., Möhler, O., Skrotzki, J., Vragel, M., and Wagner, R.: Influence of particle size and shape on the backscattering linear depolarisation ratio of small ice crystals cloud chamber measurements in the context of contrail and cirrus microphysics, Atmos. Chem. Phys. Discuss., 12, 15453-15502, doi:10.5194/acpd-12-15453-2012, 2012.

Shiraiwa, M., Ammann, M., Koop, T., and Pöschl, U.: Gas uptake and chemical aging of semisolid organic aerosol particles, Proc. Natl. Acad. Sci. USA, 108, 11003-11008, 2011.

Tong, H.-J., Reid, J. P., Bones, D. L., Luo, B. P., and Krieger, U. K.: Measurements of the timescales for the mass transfer of water in glassy aerosol at low relative humidity and ambient temperature, Atmos. Chem. Phys., 11, 4739-4754, doi:10.5194/acp-11-47392011, 2011.

Vali, G.: Repeatability and randomness in heterogeneous freezing nucleation, Atmos. Chem. Phys., 8, 5017-5031, doi:10.5194/acp-8-5017-2008, 2008.

Wagner, R., Benz, S., Möhler, O., Saathoff, H., and Schurath, U.: Probing ice clouds by broadband mid-infrared extinction spectroscopy: case studies from ice nucleation experiments in the AIDA aerosol and cloud chamber, Atmos. Chem. Phys., 6, 47754800, doi:10.5194/acp-6-4775-2006, 2006a.

Wagner, R., Bunz, H., Linke, C., Möhler, O., Naumann, K. H., Saathoff, H., Schnaiter, M., and Schurath, U.: Chamber Simulations of Cloud Chemistry: The AIDA Chamber, in: Proceedings of the NATO Advances Research Workshop on Environmental Simulation Chambers: Application to Atmospheric Chemical Processes, held in Zakopane, Poland, from 1 to 4 October 2004, edited by: Barnes, I. and Rudzinski, K. J., Springer, 2006b.
Wagner, R., Benz, S., Bunz, H., Möhler, O., Saathoff, H., Schnaiter, M., Leisner, T., and Ebert, V.: Infrared Optical Constants of Highly Diluted Sulfuric Acid Solution Droplets at Cirrus Temperatures, J. Phys. Chem. A, 112, 11661-11676, 2008.

Wagner, R., Linke, C., Naumann, K. H., Schnaiter, M., Vragel, M., Gangl, M., and Horvath, H.: A review of optical measurements at the aerosol and cloud chamber AIDA, J. Quant. Spectrosc. Radiat. Transfer, 110, 930-949, 2009.

Wagner, R., Möhler, O., Saathoff, H., Schnaiter, M., and Leisner, T.: High variability of the heterogeneous ice nucleation potential of oxalic acid dihydrate and sodium oxalate, Atmos. Chem. Phys., 10, 7617-7641, doi:10.5194/acp-10-7617-2010, 2010.

Wagner, R., Möhler, O., Saathoff, H., Schnaiter, M., and Leisner, T.: New cloud chamber experiments on the heterogeneous ice nucleation ability of oxalic acid in the immersion mode, Atmos. Chem. Phys., 11, 2083-2110, doi:10.5194/acp-11-2083-2011, 2011.

Wilson, T. W., Murray, B. J., Wagner, R., Möhler, O., Saathoff, H., Schnaiter, M., Skrotzki, J., Price, H. C., Malkin, T. L., Dobbie, S., and Al-Jumur, S. M. R. K.: Glassy aerosols with a range of compositions nucleate ice heterogeneously at cirrus temperatures, Atmos. Chem. Phys., 12, 8611-8632, doi:10.5194/acp-128611-2012, 2012.

Wise, M. E., Baustian, K. J., Koop, T., Freedman, M. A., Jensen, E. J., and Tolbert, M. A.: Depositional ice nucleation onto crystalline hydrated $\mathrm{NaCl}$ particles: a new mechanism for ice formation in the troposphere, Atmos. Chem. Phys., 12, 1121-1134, doi:10.5194/acp-12-1121-2012, 2012.

Zakharova, N. T. and Mishchenko, M. I.: Scattering properties of needlelike and platelike ice spheroids with moderate size parameters, Appl. Opt., 39, 5052-5057, 2000.

Zobrist, B., Marcolli, C., Koop, T., Luo, B. P., Murphy, D. M., Lohmann, U., Zardini, A. A., Krieger, U. K., Corti, T., Cziczo, D. J., Fueglistaler, S., Hudson, P. K., Thomson, D. S., and Peter, T.: Oxalic acid as a heterogeneous ice nucleus in the upper troposphere and its indirect aerosol effect, Atmos. Chem. Phys., 6, 3115-3129, doi:10.5194/acp-6-3115-2006, 2006.

Zobrist, B., Marcolli, C., Pedernera, D. A., and Koop, T.: Do atmospheric aerosols form glasses?, Atmos. Chem. Phys., 8, 52215244, doi:10.5194/acp-8-5221-2008, 2008.

Zobrist, B., Soonsin, V., Luo, B. P., Krieger, U. K., Marcolli, C., Peter, T., and Koop, T.: Ultra-slow water diffusion in aqueous sucrose glasses, Phys. Chem. Chem. Phys., 13, 3514-3526, 2011.

Zuberi, B., Bertram, A. K., Koop, T., Molina, L. T., and Molina, M. J.: Heterogeneous freezing of aqueous particles induced by crystallized $\left(\mathrm{NH}_{4}\right)_{2} \mathrm{SO}_{4}$, ice, and letovicite, J. Phys. Chem. A, 105, 6458-6464, 2001. 